\title{
Enzyme-Triggered Morphological Transition of Peptide Nanostructures for Tumor-Targeted Drug Delivery and Enhanced Cancer Therapy
}

DOI:

10.1021/acsami.9b03519

\section{Document Version}

Accepted author manuscript

Link to publication record in Manchester Research Explorer

Citation for published version (APA):

Cao, M., Lu, S., Wang, N., Xu, H., Cox, H., Li, R., Waigh, T., Han, Y., Wang, Y., \& Lu, J. R. (2019). EnzymeTriggered Morphological Transition of Peptide Nanostructures for Tumor-Targeted Drug Delivery and Enhanced Cancer Therapy. A C S Applied Materials and Interfaces, 16357-16366. https://doi.org/10.1021/acsami.9b03519

\section{Published in:}

A C S Applied Materials and Interfaces

\section{Citing this paper}

Please note that where the full-text provided on Manchester Research Explorer is the Author Accepted Manuscript or Proof version this may differ from the final Published version. If citing, it is advised that you check and use the publisher's definitive version.

\section{General rights}

Copyright and moral rights for the publications made accessible in the Research Explorer are retained by the authors and/or other copyright owners and it is a condition of accessing publications that users recognise and abide by the legal requirements associated with these rights.

\section{Takedown policy}

If you believe that this document breaches copyright please refer to the University of Manchester's Takedown Procedures [http://man.ac.uk/04Y6Bo] or contact uml.scholarlycommunications@manchester.ac.uk providing relevant details, so we can investigate your claim.

\section{OPEN ACCESS}


Biomacromolecules 2019, 209, 3601-3610.

https://doi.org/10.1021/acs.biomac.9b01009

\section{Reversible Thermoresponsive Peptide-PNIPAM Hydrogels for Controlled Drug}

\section{Delivery}

Meiwen Cao, ${ }^{*}{ }^{\dagger}$ Yu Wang,${ }^{\dagger}$ Xuzhi Hu, ${ }^{\ddagger}$ Haoning Gong, ${ }^{\dagger}$ Ruiheng Li, ${ }^{\ddagger}$ Henry Cox,${ }^{\ddagger}$ Jing Zhang, ${ }^{\ddagger}$ Thomas A. Waigh, ${ }^{\ddagger},+$ Hai Xu, ${ }^{*},{ }^{\dagger}$ and Jian Ren $\mathrm{Lu}^{*},+$

${ }^{\dagger}$ State Key Laboratory of Heavy Oil Processing and Centre for Bioengineering and Biotechnology, College of Chemical Engineering, China University of Petroleum (East China), 66 Changjiang West Road, Qingdao 266580, China

${ }^{\star}$ Biological Physics Laboratory, School of Physics and Astronomy, University of Manchester, Schuster Building, Oxford Road, Manchester M13 9PL, U.K.

+ Photon Science Institute, University of Manchester, Oxford Rd., Manchester M13 9PL, U.K.

\section{Corresponding Authors}

* E-mail: mwcao@upc.edu.cn $\quad$ (M.C.); $\quad$ xuh@upc.edu.cn $\quad$ (H.X.); j.lu@manchester.ac.uk (J.R.L.) 


\section{ABSTRACT}

Mixed thermoreversible gels were successfully fabricated by the addition of a thermosensitive polymer, poly(N-isopropylacrylamide) (PNIPAM), to fibrillar nanostructures self-assembled from a short peptide $\mathrm{I}_{3} \mathrm{~K}$. When the temperature was increased above the lower critical solution temperature (LCST) of the PNIPAM, the molecules collapsed to form condensed globular particles, which acted as cross-links to connect different peptide nanofibrils and freeze their movements, resulting in the formation of a hydrogel. Since these processes were physically driven, such hydrogels could be reversibly switched between the sol and gel state as a function of temperature. As a model peptide, $\mathrm{I}_{3} \mathrm{~K}$ was formulated with PNIPAM to produce a thermoreversible sol-gel system with a transition temperature of $\sim 33{ }^{\circ} \mathrm{C}$, which is just below the body temperature. The antibacterial peptide of $\mathrm{G}(\mathrm{IIKK})_{3} \mathrm{I}-\mathrm{NH}_{2}$ could be conveniently encapsulated in the hydrogel by addition of the solution at lower temperatures in the sol phase and then increasing the temperature to be above $33{ }^{\circ} \mathrm{C}$ for gelation. The hydrogel gave a sustained and controlled linear release of $\mathrm{G}(\mathrm{IIKK})_{3} \mathrm{I}-\mathrm{NH}_{2}$ over time. Using the peptide nanofibrils as 3D scaffolds, such thermoresponsive hydrogels mimic the extracellular matrix and could potentially be used as injectable hydrogels for minimally invasive drug delivery or tissue engineering.

KEYWORDS: Thermosensitive hydrogels, Peptide nanofibrils, PNIPAM, Sol-gel transition, Antimicrobial gels, Controlled drug delivery 


\section{INTRODUCTION}

Thermosensitive hydrogels have recently attracted great interest from both academic and industrial research communities for their biomedical and pharmaceutical applications, i.e., in drug delivery, cell culture, tissue engineering and wound dressing [1-6]. Thermoresponsive sol-gel systems are a particular kind of hydrogels that can transform from a flowing fluid (the sol phase) to a non-flowing hydrogel (the gel phase) as a function of temperature [7-10]. Such systems are advantageous when used as injectable gel-forming matrices. In the sol phase, therapeutic agents such as drugs or cells can be conveniently incorporated into the system by simple mixing of the solutions involved. When injected into a target tissue, the solution can transform to a hydrogel in situ triggered by body temperature, acting as a sustained drug release reservoir for local drug administration $[8,9,11-13]$ or a cell-growing matrix for tissue repair [14-16]. Such a process allows introduction of the hydrogels into the body interior conveniently in a minimally invasive manner. The low viscosity of the sol phase means that it can easily flow to fill a cavity, a defect or a surgical wound, enabling the hydrogel to perfectly adapt to the irregularly shaped boundaries [17]. The hydrogel drug reservoir avoids the long circulation process in the blood stream and releases the drug locally over a prolonged period of time, thereby reducing the frequency of administration as well as enhancing the efficiency of the drug targeting [18]. Moreover, the thermosensitive sol-gel phase transition does not require any organic solvents, chemical reaction or external stimulation, therefore providing a simple and safe mechanism for in vivo applications [19,20].

Poly(N-isopropylacrylamide) (PNIPAM) is one of the most popular temperature-responsive polymers. It has a lower critical solution temperature (LCST) 
of $32-34{ }^{\circ} \mathrm{C}[1,21]$ and exhibits a coil-to-globule conformational transition upon temperature increase to above the LCST due to a shift in the balance of hydrophilic and hydrophobic forces [21-23]. PNIPAM contains both hydrophilic amide groups and hydrophobic propyl groups in the monomer structure. Below the LCST, the polymer can be fully dissolved in an uncrosslinked form due to the creation of a highly structured hydration shell formed by hydrogen bonding between the amide groups and the water molecules. Above the LCST, dehydration of the amide groups occurs and the hydrophobic interaction among the propyl groups becomes strong. Water is then excluded from the molecular aggregates in a process of microphase separation, resulting in the collapse of the polymer chains and further aggregation and condensation.

PNIPAM undergoes rapid phase transitions and thus has rapid response times [24-26]. Together with their negligible cytotoxicity, PNIPAM-based thermoresponsive hydrogels have been widely exploited as therapeutic devices for drug delivery and scaffolds for tissue engineering [11,24,27]. However, most of the studies involve chemical polymerization of NIPAM monomers with other components to retain their thermoresponsiveness [28-30]. The polymerized hydrogels usually do not have the sol-gel reversibility due to the irreversible covalent bonds in their crosslinked networks and are often unsuitable as injectable systems for biomedical applications [31-34].

Short, designed peptides are often constructed from naturally occurring amino acids and amphiphilic. Their self-assembly can produce various nanostructures including fibrils, belts, tubes and vesicles. They have potential applications as drug carriers, 
since they can form hydrophobic inner cores for drug loading by solubilization and active outer surfaces for drug loading by molecular binding [35-38]. Some peptides can also produce hydrogels by forming three dimensional networks that incorporate self-assembled fibrillar nanostructures. However, these peptide hydrogels usually do not have thermosensitive properties [39-42].

Self-assembling peptide-based hydrogels with thermoresponsive action could work as attractive scaffolds for cell culture and controlled drug delivery. One effective strategy to equip peptide hydrogels with thermoresponsibility is to produce thermoreversible sol-gel systems by utilizing a fully non-covalent process with dynamic and reproducible forces to trigger hydrogel formation such as hydrogen bonding, electrostatic interaction, ionic bonding, and physical entanglement [43-45]. In the context of this work, we have chosen a group of short peptides represented by $\mathrm{I}_{3} \mathrm{~K}$, that can all self-assemble into long ordered nanofibrils [46,47]. Taking advantage of the thermosensitivity of PNIPAM and the drug carrying property of the peptide nanofibrils, we developed thermoresponsive hydrogels that are composed of PNIPAM and fibrillar nanostructures self-assembled from the short peptide amphiphiles. The mixed hydrogel systems adopt 3 dimensional networks which are physically crosslinked. These reversible temperature-sensitive gelation systems were based on the simple physical mixing of the PNIPAM and peptide self-assembled structures. The systems exhibited a sharp reversible sol-gel transition around $33{ }^{\circ} \mathrm{C}$, close to the body temperature of $37{ }^{\circ} \mathrm{C}$ [20]. Therefore, the current systems can undergo a sol-gel transition near the physiological conditions by heat-induced changes in molecular conformation. The antibacterial peptide $\mathrm{G}(\mathrm{IIKK})_{3} \mathrm{I}-\mathrm{NH}_{2}[48,49]$ was successfully encapsulated in the hydrogels by simple mixing of the solutions at room temperature 
and then the temperature was increased above $33{ }^{\circ} \mathrm{C} . \mathrm{G}(\mathrm{IIKK})_{3} \mathrm{I}-\mathrm{NH}_{2}$ could then be released from the hydrogels in a sustained linear manner. Therefore, the systems may be used as injectable hydrogels, which can be triggered by body temperature to undergo in situ gelation for minimally invasive drug delivery.

\section{EXPERIMENTAL}

\subsection{Materials}

The peptides $\mathrm{CH}_{3} \mathrm{CO}-\mathrm{I}_{3} \mathrm{~K}-\mathrm{NH}_{2} \quad\left(\mathrm{I}_{3} \mathrm{~K}, \quad\right.$ purity $\left.>98 \%\right), \quad \mathrm{G}(\mathrm{IIKK})_{3} \mathrm{I}-\mathrm{NH}_{2} \quad$ and FITC-G(IIKK) $)_{3} \mathrm{I}-\mathrm{NH}_{2}$ (purity > 96\%) were purchased from Shanghai Top-Peptide Biotechnology Co. Ltd. PNIPAM (Mw 20,000-40,000) was purchased from Sigma-Aldrich. Escherichia coli (E. coli, ATCC 25922), Staphylococcus aureus (S. aureus, ATCC 6538), and Pseudomonas aeruginosa (P. aeruginosa, ATCC 9027) bacteria were obtained from the American Type Culture Collection (ATCC) and grown in Tryptic soy broth. The other chemicals were all purchased from Sigma-Aldrich and used as received. Water $(18 \mathrm{M} \Omega \mathrm{cm})$ was purified from a Milli-Q system and used in all the experiments.

\subsection{Solution Preparation and Hydrogel Formation}

$\mathrm{I}_{3} \mathrm{~K}$ powder was dissolved in water to make a solution of $12.0 \mathrm{mM}$ with sonication for 30 min and then incubated at room temperature for at least three days. PNIPAM was dissolved in Tris-buffer at $\mathrm{pH} 7.4$ to make a solution of $20 \mathrm{mg} / \mathrm{mL}$ and aged for at least two days. The $\mathrm{I}_{3} \mathrm{~K}$ solution and the PNIPAM solution were then mixed at a defined volume ratio at room temperature to obtain the final solution using a vortex mixer for $10 \mathrm{~min}$. For hydrogel formation, the $\mathrm{I}_{3} \mathrm{~K} / \mathrm{PNIPAM}$ mixed solution was heated in a water bath to increase the temperature above $33{ }^{\circ} \mathrm{C}$ and gelation was 
observed when the transparent flowing solution became opaque and non-flowing. It should be noted that the $I_{3} \mathrm{~K}$ solution itself will undergo gelation at concentrations higher than $10 \mathrm{mM}$ [46], therefore, the $\mathrm{I}_{3} \mathrm{~K}$ concentration was kept below $10 \mathrm{mM}$ in the $\mathrm{I}_{3} \mathrm{~K} / \mathrm{PNIPAM}$ mixed soltuions in this study.

\subsection{Atomic Force Microscopy (AFM)}

A MultiMode Nanoscope VIII equipment (Bruker, Germany) was used for AFM imaging measurements. Samples were prepared by depositing 5-10 $\mu \mathrm{L}$ of the solution/hydrogel on a freshly cleaved mica surface for $\sim 30 \mathrm{~s}$ at room temperature $/ 40{ }^{\circ} \mathrm{C}$ and then dried under a nitrogen stream. The tapping mode was used for image capture with TESP-V2 silicon probes. The cantilevers had a nominal spring constant of $42 \mathrm{~N} \mathrm{~m}^{-1}$. The images were analyzed with the NanoScope Analysis software of version 1.40 .

\subsection{Transmission Electron Microscopy (TEM)}

Negative-staining TEM measurements were performed on a JEOL JEM-1400 equipment at an accelerating voltage of $200 \mathrm{kV}$. Briefly, the sample was prepared as follows. A drop of sample solution was first placed on a copper grid with carbon Formvar coating for adsorption of $\sim 5 \mathrm{~min}$. The excess fluid was then wicked away by a filter paper and the grid was transferred onto a drop of uranyl acetate solution ( $2 \%$ w/v) and stained for $\sim 2 \mathrm{~min}$.

\subsection{UV-Vis Measurements}

To evaluate the turbidity, the absorption of the solution at $400 \mathrm{~nm}$ was measured on a UV-1700 spectrophotometer (Phama Spec, Shimadzu) with a home-made temperature 
controller. When the temperature was below the LCST, the solution was transparent and had low light absorption. When the temperature was above the LCST, the solution became a hydrogel and was opaque with high light absorption.

For the determination of the concentration of FITC-G(IIKK) $)_{3} \mathrm{I}-\mathrm{NH}_{2}$, a series of the antimicrobial peptide solutions with known concentrations were first prepared. The light absorption values at $495 \mathrm{~nm}$ were then used to produce a standard curve. The concentration of FITC-G(IIKK $)_{3} \mathrm{I}-\mathrm{NH}_{2}$ that was released was calculated by referring to the standard curve.

\subsection{Differential Scanning Calorimetry (DSC)}

The DSC measurements were performed on a micro-DSC (Setaram-France) instrument. The data were obtained in the temperature range of $5-95{ }^{\circ} \mathrm{C}$ at a heating rate of $1{ }^{\circ} \mathrm{C} / \mathrm{min}$.

\subsection{Circular Dichroism (CD)}

CD measurements were performed on a MOS-450 spectrometer (Biologic, France). The solution samples were measured directly in a $0.5 \mathrm{~mm}$ quartz cell. The spectra were collected over a wavelength range of $190-260 \mathrm{~nm}$ with a $0.5 \mathrm{~nm}$ step. Three repeats were performed for each sample and the averaged values were presented.

\subsection{Small Angle Neutron Scattering (SANS)}

SANS experiments were performed on the LOQ instrument at the ISIS Neutron Facility, Rutherford Appleton Laboratory (Oxford, UK). The solutions were prepared using $\mathrm{D}_{2} \mathrm{O}$ to dissolve both the peptides and PNIPAM and then mixed. The SANS 
spectra were collected with disc-shaped silica cells with a path length of $2.0 \mathrm{~mm}$. A water bath was used to control the temperature. The sample was equilibrated at each temperature for $30 \mathrm{~min}$ before measurements. The incident wavelength of the neutrons was set to be $2.2-10.0 \AA$ at $25 \mathrm{~Hz}$. The samples were positioned $4.05 \mathrm{~m}$ from the detector. The data were corrected for the incident spectrum, the wavelength dependence of the sample transmission, the relative efficiency of detector, and the $\mathrm{D}_{2} \mathrm{O}$ background subtracted. The absolute scaling was obtained with respect to the scattering of a partially deuterated polystyrene standard. The data fit was performed using SansView 3.1.2. The models used for the data fits are described in the Supporting Information.

\subsection{Rheological Measurements}

Frequency sweep rheology measurements were made on a Haake MARS III modular rheometer (Thermo Scientific) that operated in a cone-plate mode at different temperatures. The sample temperature was controlled using a heating circulator, which could heat the sample stage gradually. Measurements of the storage modulus G' and loss modulus $\mathrm{G}^{\prime \prime}$ as a function of frequency were performed over the range $0.1-10 \mathrm{~Hz}$.

\subsection{Toxicity Evaluation}

The toxicity of the $\mathrm{I}_{3} \mathrm{~K} / \mathrm{PNIPAM}$ mixed hydrogel was evaluated using tetrazolium reduction (the MTT assay). Briefly, the mixed solution $\left(\mathrm{I}_{3} \mathrm{~K}: 6 \mathrm{mM}\right.$, PNIPAM: 2 $\mathrm{mg} / \mathrm{mL}$ ) was first prepared in Tris buffer of $\mathrm{pH} 7.4$ and incubated for at least $24 \mathrm{~h}$. Then, $150 \mu \mathrm{L}$ of the mixed solution was added into a 48 -well tissue culture polystyrene (TCPS) plate. By incubating at $37{ }^{\circ} \mathrm{C}$ for $2 \mathrm{~h}$ the mixed solution turned 
into a hydrogel. Then, $150 \mu \mathrm{L}$ of NIH 3 T3 cells $\left(1 \times 10^{6}\right.$ cells $/ \mathrm{mL}$, preseeded at $37{ }^{\circ} \mathrm{C}$ in Iscove's modified Dubelcco's medium (IMDM) with 10\% (v/v) fetal bovine serum (FBS)) was introduced into each well and incubated at $37{ }^{\circ} \mathrm{C}$ under $5 \%(\mathrm{v} / \mathrm{v}) \mathrm{CO}_{2}$. The cells seeded in the wells without the $\mathrm{I}_{3} \mathrm{~K} / \mathrm{PNIPAM}$ mixtures were used as control. The culture medium was refreshed every $72 \mathrm{~h}$. After cell culturing, $30 \mu \mathrm{L}$ of MTT (5 $\mathrm{mg} / \mathrm{mL}$ ) was added into each well and incubated at $37{ }^{\circ} \mathrm{C}$ for another $4 \mathrm{~h}$. Then the liquid was removed from all the wells and $200 \mu \mathrm{L}$ of dimethyl sulfoxide (DMSO) was added into each well to dissolve the precipitated formazan. The absorbance at $490 \mathrm{~nm}$ $\left(\mathrm{A}_{490}\right)$ was obtained on a microplate autoreader (Molecular Devices, M2e). For the $\mathrm{I}_{3} \mathrm{~K} / \mathrm{PNIPAM}$ samples, the gel-coated wells without cells were used as a reference for absorbance measurement.

\subsection{Determination of Antibacterial Activity}

The antibacterial activity of $\mathrm{G}(\mathrm{IIKK})_{3} \mathrm{I}-\mathrm{NH}_{2}$ against different bacteria was evaluated using the MTT assay and the minimum inhibitory concentration (MIC) was determined. Briefly, $\mathrm{G}(\mathrm{IIKK})_{3} \mathrm{I}-\mathrm{NH}_{2}$ solution was prepared in a buffer at $\mathrm{pH} 7.4$ and sterilized with ultraviolet radiation for a few hours. The bacteria were cultured overnight and $200 \mu \mathrm{l}$ was pipetted into a 96-well plate. The optical density at $600 \mathrm{~nm}$ $\left(\mathrm{OD}_{600}\right)$ was then obtained using a Sunrise microplate reader (Tecan Group Ltd.). The bacterial culture was calibrated at an $\mathrm{OD}_{600}$ of 0.8 and diluted in the broth at 1:2000 (v/v). The G(IIKK) $)_{3} \mathrm{I}-\mathrm{NH}_{2}$ solutions were two-fold diluted in the buffer to obtain the total volume of $100 \mu \mathrm{l}$ in each well of the 96-well plates. Then, $100 \mu \mathrm{l}$ of bacterial inoculum was added into each well to mix with the $\mathrm{G}(\mathrm{IIKK})_{3} \mathrm{I}-\mathrm{NH}_{2}$ solution. The bacteria were then cultured at $40{ }^{\circ} \mathrm{C}$ for $18 \mathrm{~h}$ with shaking at $100 \mathrm{rpm}$. Subsequently, the $\mathrm{OD}_{600}$ was measured. The MIC was determined as the lowest $\mathrm{G}(\mathrm{IIKK})_{3} \mathrm{I}-\mathrm{NH}_{2}$ 
concentration at which bacterial growth was totally inhibited. The experiments were repeated three times and three technical replicates were applied for each measurement. Errors were calculated using standard deviations of the replicate measurements.

\subsection{Drug Loading and Release}

To determine peptide release from the hydrogel, the fluorescently labeled FITC-G(IIKK) $)_{3} \mathrm{I}-\mathrm{NH}_{2}$ was used. FITC-G(IIKK) $)_{3} \mathrm{I}-\mathrm{NH}_{2}$ was mixed into the PNIPAM $/ \mathrm{I}_{3} \mathrm{~K}$ solution directly at room temperature, which can then be easily encapsulated in the hydrogel by increasing the temperature of the system to $40{ }^{\circ} \mathrm{C}$. To determine the peptide release from the gel, $2.0 \mathrm{~mL}$ of water was added to a tube that contained the hydrogel. At the allotted time intervals, $100 \mu \mathrm{L}$ of the supernatant was withdrawn and replaced by the same amount of fresh water pre-warmed at $40^{\circ} \mathrm{C}$. The absorbance of the supernatant was measured at $495 \mathrm{~nm}$. The released FITC-G(IIKK) $)_{3} \mathrm{I}-\mathrm{NH}_{2}$ concentration was calculated with respect to the standard curve (Figure S4).

\section{RESULTS AND DISCUSSION}

\subsection{Characterization of the reversible sol-gel transition}

The $\mathrm{I}_{3} \mathrm{~K}$ solutions (Figure $\mathrm{S} 1$, Supporting Information) of concentrations of $\leq 10 \mathrm{mM}$ were transparent and flowed freely at both $25{ }^{\circ} \mathrm{C}$ and $40{ }^{\circ} \mathrm{C}$. The PNIPAM solutions up to the concentration of $80 \mathrm{mg} / \mathrm{ml}$ were transparent at $25^{\circ} \mathrm{C}$, but became opaque at $40{ }^{\circ} \mathrm{C}$ due to the coil-to-globule phase transition [23]. However, the PNIPAM solution remained liquid-like in both cases. In contrast, the solutions of the PNIPAM/I ${ }_{3} \mathrm{~K}$ mixtures were transparent and flowed freely at $25^{\circ} \mathrm{C}$ (Figure 1a), but became self-supporting opaque hydrogels above $33{ }^{\circ} \mathrm{C}$ (Figure 1b). Gelation was 
demonstrated using the simple test-tube inversion method. The concentration window for gelation was determined to be over $4-12 \mathrm{mM}$ for $\mathrm{I}_{3} \mathrm{~K}$ (the $\mathrm{I}_{3} \mathrm{~K}$ solution became opaque above $12 \mathrm{mM}$ ) and above $0.5 \mathrm{mg} / \mathrm{mL}$ for PNIPAM. The hydrogel formation was very quick and formed within 5 seconds above a temperature of $33{ }^{\circ} \mathrm{C}$. The opaque hydrogel became a transparent solution again when the solution was cooled down and the sol-gel transition is thus thermoreversible. We performed 20 cycles of the process of the sol-gel interconversion and the transition showed no hysteresis. UV-Vis absorbance at $400 \mathrm{~nm}$ was used to follow changes in solution turbidity with temperature variation (Figure 1c) to indicate the gelation kinetics. The results show that the solution can change fully reversibly between transparent (low turbidity) and highly turbid states without significant hysteresis. The turbidity increased sharply at a temperature of $33{ }^{\circ} \mathrm{C}$, confirming the sol-gel transition temperature $\left(T_{\text {sol-gel }}\right)$, which coincided with the temperature when the solution did not flow using the vial inversion method.

The peptide and PNIPAM concentrations were also varied and no significant changes in $T_{\text {sol-gel }}$ were found for all of the samples. The LCST was detected at roughly the same temperature for all the samples, indicating that the interaction of the polymer with the peptide and its anchoring on the $\beta$-sheet fiber has a minimal effect on the LCST temperature [50].

The phase transition of the system was further investigated by DSC measurements, with $\mathrm{I}_{3} \mathrm{~K}$ and PNIPAM solutions used as controls (Figure 1d). The $\mathrm{I}_{3} \mathrm{~K}$ curve showed no peak in the whole temperature range, indicating no phase transition. For the PNIPAM solution and the PNIPAM/I ${ }_{3} \mathrm{~K}$ mixed solution, their DSC curves gave quite 
similiar profiles, both displaying a sharp endothermic peak at $\sim 33{ }^{\circ} \mathrm{C}$ that can be ascribed to the phase transition of PNIPAM. The results indicate that the coil-to-globule transition of PNIPAM molecules was the only process upon heating of the PNIPAM/ $/{ }_{3} \mathrm{~K}$ mixed solution, which drove the sol-gel transition of the system.
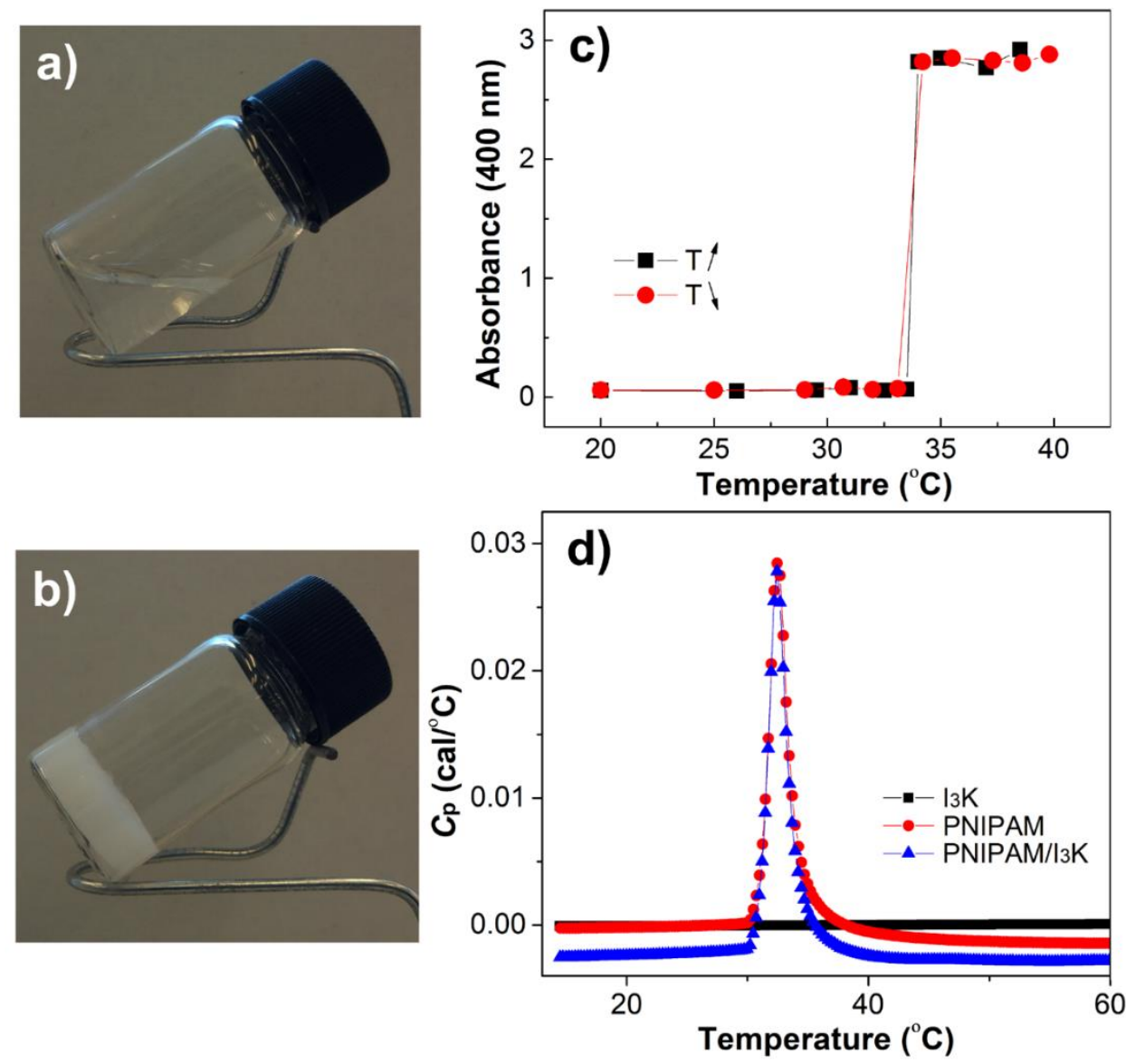

Figure 1. Photographs of the sol-gel transition for the PNIPAM/I ${ }_{3} \mathrm{~K}$ mixed system (a) at $25{ }^{\circ} \mathrm{C}$ and (b) at $40{ }^{\circ} \mathrm{C}$. (c) Variation of the turbidities of the systems with temperature changes. (d) DSC curves of the solutions of $\mathrm{I}_{3} \mathrm{~K}$, PNIPAM and PNIPAM/I ${ }_{3} \mathrm{~K}$ mixture. The concentration was $6.0 \mathrm{mM}$ for $\mathrm{I}_{3} \mathrm{~K}$ and $20.0 \mathrm{mg} / \mathrm{mL}$ for PNIPAM at $\mathrm{pH} 7.4$.

Besides $\mathrm{I}_{3} \mathrm{~K}$, we also chose 3 other peptides that can form fibrillar structures, the positively charged $\mathrm{A}_{6} \mathrm{~K}$ [51] and $\mathrm{I}_{3} \mathrm{QGK}$ [52] and the negatively charged Fmoc-FF-COOH [53], to form mixed solutions with PNIPAM. These short peptides 
are all amphiphilic and can self-assemble into fibrillar structures above their critical aggregation concentrations (CACs) (Figure S2, Supporting Information), which are typically below $1 \mathrm{mM}$ under the physiologically mimicking environment. The results showed that over relatively lower peptide concentrations where the peptides cannot form hydrogels by themselves, the PNIPAM/peptide mixtures produced a clear sol-gel transition upon temperature increase to be above the LCST of PNIPAM (Figure S2, Supporting Information). This reveals that the thermoresponsive sol-gel transition is a general process for the PNIPAM/peptide mixed systems that does not depend on the charges of the peptides or the shapes and diameters of the peptide self-assembled fibrillar structures.

TEM and AFM were further used to characterize the morphologies of $\mathrm{I}_{3} \mathrm{~K}$ self-assembled structures as well as the PNIPAM/I ${ }_{3} \mathrm{~K}$ mixtures (Figure 2). For $\mathrm{I}_{3} \mathrm{~K}$ itself, many long fibrils with diameters around $10.0 \pm 1.5 \mathrm{~nm}$ were observed (Figure 2a), consistent with our previous findings $[46,47]$. The surface of these fibrils was smooth, although there were periodic fluctuations that indicate the helical nature of the structures. For the PNIPAM/ $\mathrm{I}_{3} \mathrm{~K}$ mixtures at $25{ }^{\circ} \mathrm{C}$, both TEM and AFM images showed nanofibrils with rough surface. Many small swollen protrusions were found distributed along the fibrillar long axes (Figure 2b). The height fluctuations of these protrusions were in the range of 0-25 nm (inset of Figure 2b). These swollen regions were believed to be from collapsed PNIPAM segments, formed during the drying process of sample preparation. For the PNIPAM/I $\mathrm{I}_{3} \mathrm{~K}$ mixtures at $40{ }^{\circ} \mathrm{C}$ (Figure 2c), the $\mathrm{I}_{3} \mathrm{~K}$ fibrils showed a morphological diversity. First, some fibrils with even higher surface roughness and larger swollen protrusions can be found (indicated by the red arrow in Figure 2c), which were caused by the association of PNIPAM molecules on 
the fibril surface. Second, some larger fibril bundles came into presence (indicated by the green arrow), which were suggested to come from lateral packing of various fibrils by using collapsed PNIPAM as a glue. Moreover, many larger bulges with sizes of 30-60 nm (inset of Figure 2c, AFM image) appeared in both TEM and AFM images. These bulges must be the collapsed PNIPAM aggregates (Figure S3) because of their high similarity in morphology. Some of these bulges are located at the junction points of the fibrillar network and acted as cross-links to connect different fibrils (inset of Figure 2c, TEM image). The increased surface roughness and big bulges highly enhanced steric hindrance and friction force of fibril movement [54]. All these results demonstrated that the temperature-induced PNIPAM coil-to-globule transition can effectively modulate the strength and number of the fibril cross-links, stabilizing the 3D network of the fibrils and facilitating gelation of the system. 

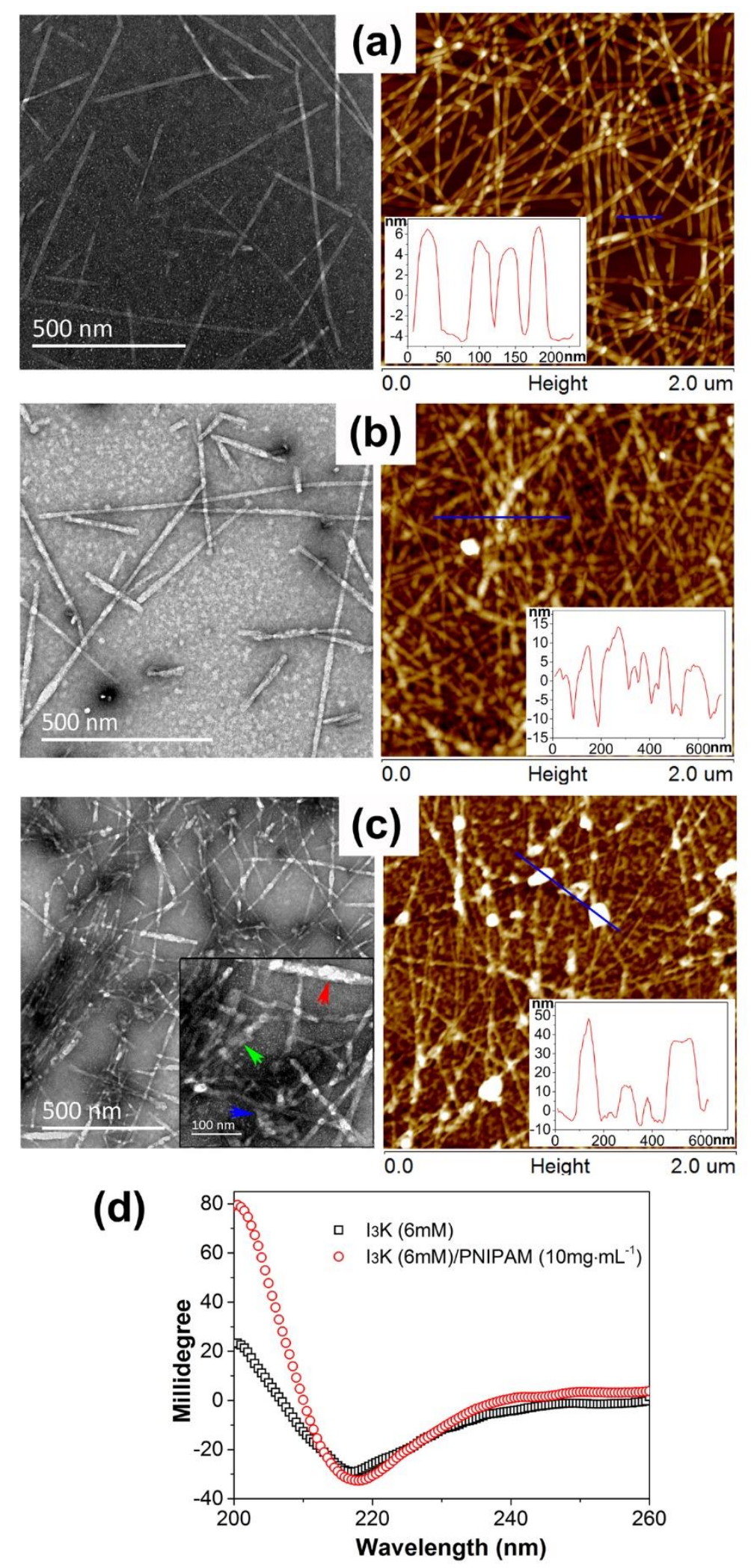

Figure 2. TEM (left panel) and AFM (right panel) images of (a) the self-assembled structures of $\mathrm{I}_{3} \mathrm{~K}(6.0 \mathrm{mM}, \mathrm{pH} 7.4)$ and the aggregates of the $\mathrm{I}_{3} \mathrm{~K}$ nanofibrils and PNIPAM (b) at $25{ }^{\circ} \mathrm{C}$ and (c) at $40{ }^{\circ} \mathrm{C}$. The insets of AFM images show height 
profiles that correspond to the blue lines. The inset TEM image shows the magnified local area. The red arrow points to the thicker nanofibril with rough surface. The green arrow points to the laterally stacked nanofibrils. The blue arrow points to the PNIPAM aggregates that join different peptide nanofibrils. (d) CD spectra as a function of wavelength for the $\mathrm{I}_{3} \mathrm{~K}$ solution and the PNIPAM/ $\mathrm{I}_{3} \mathrm{~K}$ mixture at $25^{\circ} \mathrm{C}$.

$\mathrm{CD}$ spectra were used to characterize the secondary structures of $\mathrm{I}_{3} \mathrm{~K}$ in different cases. $\mathrm{I}_{3} \mathrm{~K}$ itself took a typical $\beta$-sheet structure, as indicated by the $\mathrm{CD}$ spectrum with a negative peak at around $218 \mathrm{~nm}$ (Figure 2d) [46,47]. For the PNIPAM/I ${ }_{3} \mathrm{~K}$ mixture, the $\mathrm{CD}$ spectrum showed a similar profile to that of $\mathrm{I}_{3} \mathrm{~K}$ itself, indicating that $\mathrm{I}_{3} \mathrm{~K}$ retained the same $\beta$-sheet structure. The results showed that interaction between the $\mathrm{I}_{3} \mathrm{~K}$ nanofibrils and PNIPAM did not affect the molecular packing of the $\mathrm{I}_{3} \mathrm{~K}$ nanofibrils.

SANS measurements were used to probe the structural characteristics of the $\mathrm{I}_{3} \mathrm{~K}$ nanofibrils and the PNIPAM/I ${ }_{3} \mathrm{~K}$ mixtures at shorter length scales (Figure 3 and Table $\mathrm{S} 1$ in Supporting Information) [55,56]. For the $\mathrm{I}_{3} \mathrm{~K}$ nanofibrils, the SANS spectra obtained at $25{ }^{\circ} \mathrm{C}$ and $40{ }^{\circ} \mathrm{C}$ showed almost the same profiles (Figure 3a). The nanofibrils were therefore stable and remained unchanged in structure upon temperature change. The scattering curves were well-fitted with a flexible cylinder model as schematically illustrated in Figure S5, which gave a fibrillar radius of around $4.9 \mathrm{~nm}$ and a length of $>100 \mathrm{~nm}$, consistent with our previous findings $[46,47]$. For PNIPAM (Figure 3b), the scattering curve obtained at $25{ }^{\circ} \mathrm{C}$ showed a plateau in the region $<0.02 \AA^{-1}$ and the intensity decayed for $\mathrm{q}>0.02 \AA^{-1}$, characteristic of polymer solutions [57]. The curve was well fitted with the Debye model as reported 
by Nishi et al. [57], indicating that PNIPAM chains behaved as Guassian coils. However, the scattering at $40{ }^{\circ} \mathrm{C}$ showed a great increase in the intensity of the low $q$ part, indicating phase transition and formation of larger particles. An ellipsoidal model was found to fit the scattering curve well with the radii in the range 250-350 nm. Such nanostructures must be formed from the globules of PNIPAM through self-assembly driven by hydrophobic association at temperatures above the LCST. For the PNIPAM/ $\mathrm{I}_{3} \mathrm{~K}$ mixtures (Figure 3c), the scattering at $25{ }^{\circ} \mathrm{C}$ was fitted with the combined Debye/flexible cylinder models. The flexible cylinder model gave a radius of $5.3 \mathrm{~nm}$, slightly larger than that of the free $\mathrm{I}_{3} \mathrm{~K}$ nanofibrils, probably due to the moderate binding of PNIPAM on the fibrillar surface. The scattering at $40{ }^{\circ} \mathrm{C}$ also showed significant increase in the intensity of the low $q$ region. It was fitted using both the flexible cylinder model and the ellipsoid model, with structures corresponding to the $\mathrm{I}_{3} \mathrm{~K}$ nanofibrils with radii of $4.9 \mathrm{~nm}$ and the PNIPAM aggregates with radii of $270-560 \mathrm{~nm}$. The SANS results clearly showed that for the PNIPAM/I $\mathrm{K}$ mixtures, the main structural change upon the temperature increase was the coil-to-globule phase transition of the PNIPAM molecules responsible for the sol-gel transition. Thus, $T_{\text {sol-gel }}$ is the same as the LCST of the PNIPAM. The gelation was a fully physically driven process and the hydrogel was stabilized by physical entanglements between $\mathrm{I}_{3} \mathrm{~K}$ nanofibrils and PNIPAM aggregates. 

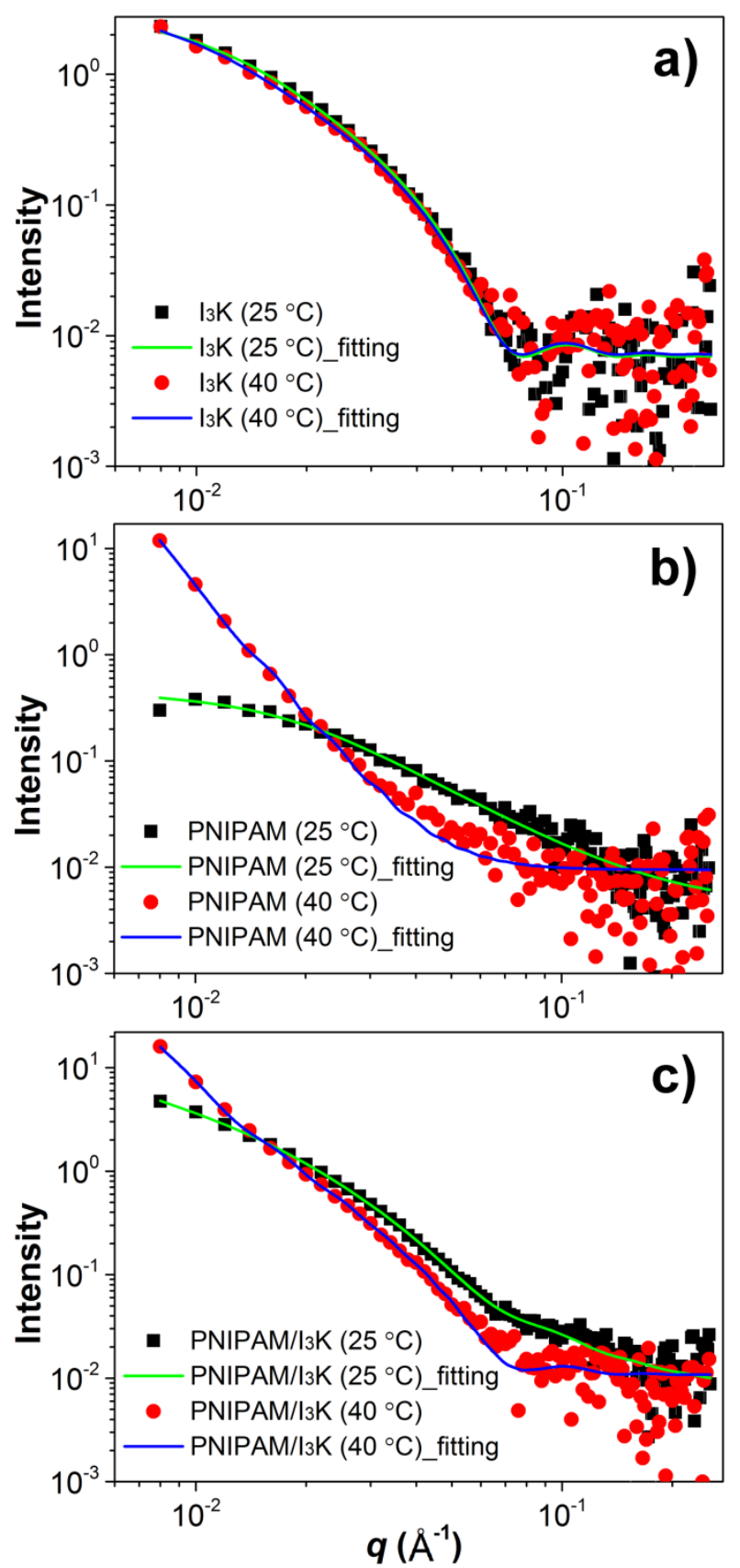

Figure 3. The scattered intensity of SANS as a function of momentum transfer $(q)$ from: (a) the $\mathrm{I}_{3} \mathrm{~K}$ solution $(6.0 \mathrm{mM})$, (b) the PNIPAM solution $(10 \mathrm{mg} / \mathrm{mL})$, and (c) the PNIPAM/I $\mathrm{I}_{3} \mathrm{~K}$ mixture in $\mathrm{D}_{2} \mathrm{O}$ at $25{ }^{\circ} \mathrm{C}$ and $40{ }^{\circ} \mathrm{C}$. The models used for the fits and the best fitted parameters can be found in Table S1 and Figure S5 of the Supporting Information.

The rheological properties of the systems were also characterized, with the results 
shown in Figure 4. For the $\mathrm{I}_{3} \mathrm{~K}$ solution (Figure 4a), G' and $\mathrm{G}^{\prime \prime}$ were relatively low to be between 10 and $70 \mathrm{~Pa}$ at $25{ }^{\circ} \mathrm{C}$, consistent with the free-flowing sol state. At $40{ }^{\circ} \mathrm{C}$ the solution remained the flowing state and the two moduli showed no obvious change. For the PNIPAM solutions (Figure $4 \mathrm{~b}$ ), $\mathrm{G}^{\prime}$ and $\mathrm{G}^{\prime \prime}$ were quite low at $25^{\circ} \mathrm{C}$, to being lower than $1 \mathrm{~Pa}$ at most of the frequency range. At $40{ }^{\circ} \mathrm{C}$, the moduli increased significantly to $30-120 \mathrm{~Pa}$. However, $\mathrm{G}^{\prime}$ and $\mathrm{G}^{\prime \prime}$ were almost the same in value, retaining their free-flowing sol state. For the $\mathrm{I}_{3} \mathrm{~K} / \mathrm{PNIPAM}$ mixtures (Figure $4 \mathrm{c}, \mathrm{d}$ ), the moduli were smaller than $10 \mathrm{~Pa}$ at $25{ }^{\circ} \mathrm{C}$ and $\mathrm{G}^{\prime}$ was usually larger than $\mathrm{G} "$. At $40{ }^{\circ} \mathrm{C}$, however, the moduli increased significantly to reach $10-1000 \mathrm{~Pa}$, forming stable hydrogels. Moreover, increase in the concentration of either PNIPAM or $\mathrm{I}_{3} \mathrm{~K}$ significantly elevated the moduli at $40{ }^{\circ} \mathrm{C}$. Thus, both polymer and peptide concentrations can be used to modulate the mechanical properties of the hydrogels. By comparing the separation space of $\mathrm{G}^{\prime}$ and $\mathrm{G}^{\prime \prime}$ curves at $40{ }^{\circ} \mathrm{C}$ in Figure $4 \mathrm{c}$ and $4 \mathrm{~d}$, we can conclude that change in PNIPAM concentration has a larger effect on modifying the moduli than change in $\mathrm{I}_{3} \mathrm{~K}$ concentration.
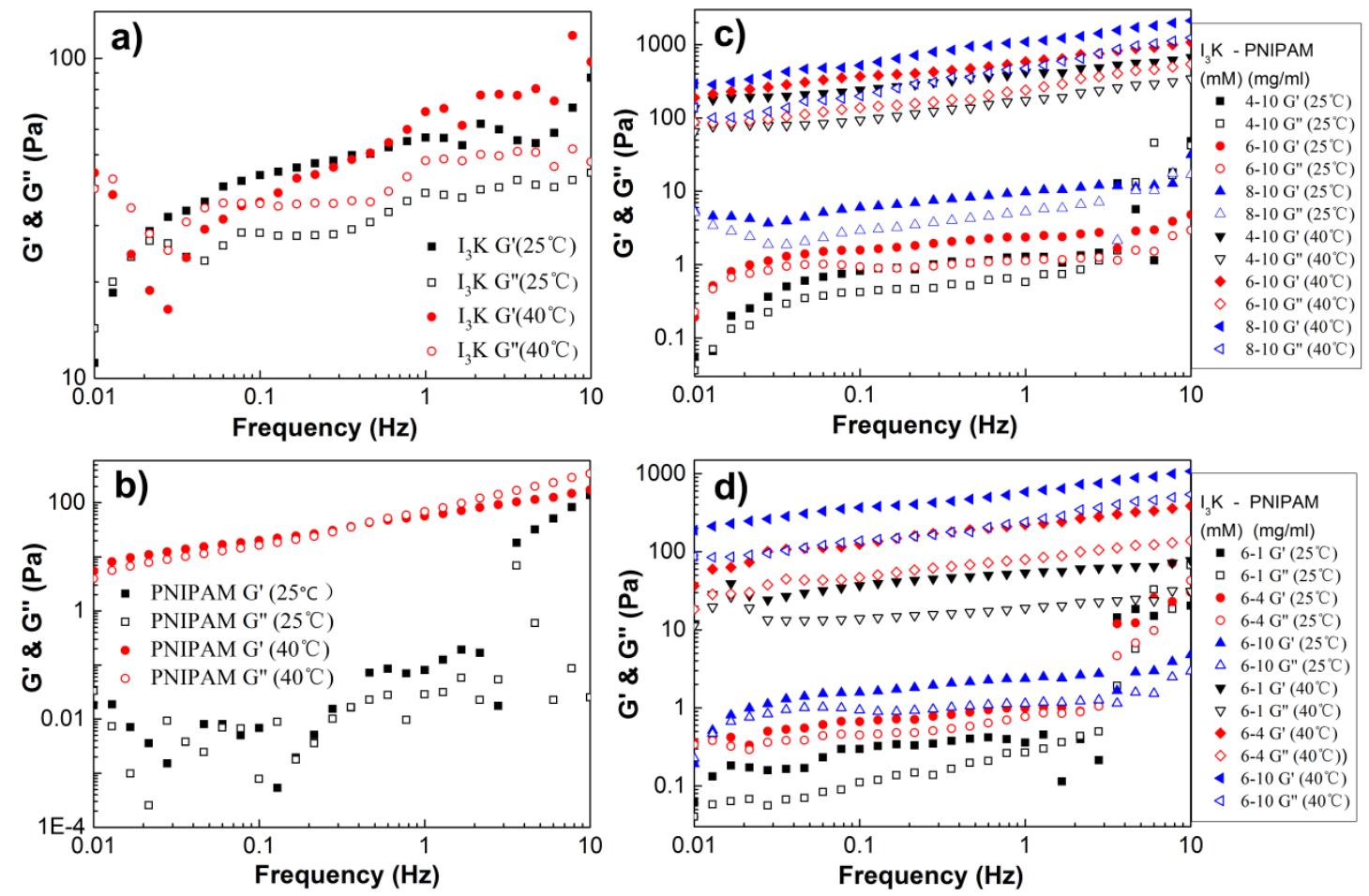
Figure 4. Linear viscoelasticity experiments measured from a cone and plate rheometer by following the storage modulus $\left(\mathrm{G}^{\prime}\right)$ and loss modulus ( $\left.\mathrm{G}^{\prime \prime}\right)$ as a function of frequency of different systems at $25^{\circ} \mathrm{C}$ and $40{ }^{\circ} \mathrm{C}$ : (a) the $\mathrm{I}_{3} \mathrm{~K}$ solution $(6.0 \mathrm{mM})$, (b) the PNIPAM solution $(10 \mathrm{mg} / \mathrm{mL})$, (c) the PNIPAM/I ${ }_{3} \mathrm{~K}$ mixture at a fixed PNIPAM concentration $(10.0 \mathrm{mg} / \mathrm{mL})$ and varied $\mathrm{I}_{3} \mathrm{~K}$ concentration, and (d) the PNIPAM $/ \mathrm{I}_{3} \mathrm{~K}$ mixture at a fixed $\mathrm{I}_{3} \mathrm{~K}$ concentration $(6.0 \mathrm{mM})$ and varied PNIPAM concentration.

\subsection{Mechanism of the sol-gel transition}

The results as shown above demonstrate a versatile approach to fabricate reversible sol-gel systems by mixing the peptide nanofibrils with the thermosensitive polymer, and the impact of temperature change is schematically illustrated in Scheme 1. At temperatures below the LCST, the polymer chain is highly hydrated and remains in a fully expanded coil state. The interactions between peptide nanofibrils and the polymer are weak and the solution is in a free-flowing state. At higher temperatures above the LCST, the polymer chain collapses into a compact globule $[29,58]$. PNIPAM molecules can attach on the nanofibrils to increase their diameters and surface roughness. A PNIPAM molecule or its aggregate can associate with 2 or more peptide nanofibrils, acting as cross-linker to cause physical entanglement. Both these aspects can increase the movement resistance and reduce the free mobility of the $\mathrm{I}_{3} \mathrm{~K} / \mathrm{PNIPAM}$ composite networks, facilitating the gelation process. When the temperature drops below the LCST again, the PNIPAM aggregates can return to the extended coil state, enabling the free movement of the $\mathrm{I}_{3} \mathrm{~K}$ nanofibrils and the reversible gel-to-sol transition. Clearly, the temperature-responsive polymer aggregation determines the reversible sol-gel transition, associated with changes in 
hydrogen bonding and weak hydrophobic interactions.

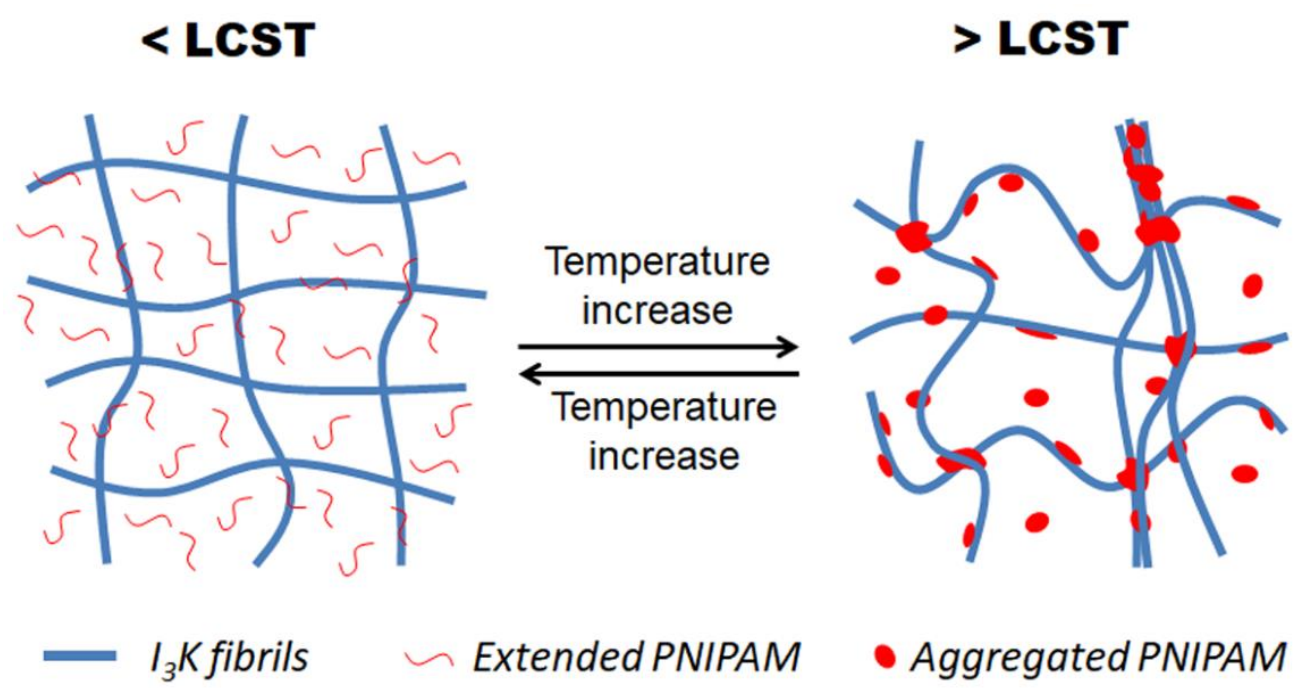

Scheme 1. Schematic diagrams of the proposed states of the $I_{3}$ K/PNIPAM networks at temperature either below or above the PNIPAM LCST (not to scale).

Evidence for the physically-driven nature of the sol-gel transition is: 1) the secondary structure from CD showing the lack of influence of the molecular arrangement of the $\mathrm{I}_{3} \mathrm{~K}$ nanofibrils by the polymer- $\mathrm{I}_{3} \mathrm{~K}$ interaction, 2) the same $T_{\text {sol-gel }}$ as the LCST of the PNIPAM in all the cases, irrespective of the polymer or peptide concentration [50], and 3) the SANS results indicating the PNIPAM phase change as the main cause for the sol-gel transition. The physical nature of the driving forces allows the sol-gel transition upon temperature change to be fully reversible. With the weak physical interaction the PNIPAM molecules are loosely attached on the nanofibrils and they cannot become further inserted into the nanofibrils to cause any structural rearrangement of the peptide molecules.

\subsection{Drug loading and release for antibacterial application}

The hydrogels containing peptide nanofibrils are morphologically similar to the extra cellular matrix structures of many tissues. Moreover, $T_{\text {sol-gel }}$ is $33{ }^{\circ} \mathrm{C}$, slightly below 
body temperature. Therefore, such systems can be triggered by body temperature for in situ gelation, which may find applications in injectable hydrogels for minimally invasive drug delivery or tissue engineering for skin and tissue repairs $[18,59]$.

$\mathrm{G}(\mathrm{IIKK})_{3} \mathrm{I}-\mathrm{NH}_{2}$ is an antibacterial peptide with high selectivity against microbial cells or tumor cells $[48,49,60]$. It was chosen as a model drug for evaluation of drug loading and release as well as its antibacterial properties. FITC-labeled $\mathrm{G}(\mathrm{IIKK})_{3} \mathrm{I}-\mathrm{NH}_{2}$ was used in experiments for the easy determination of peptide concentrations. It was mixed into the PNIPAM/I ${ }_{3} \mathrm{~K}$ aqueous solution directly at $25^{\circ} \mathrm{C}$. The premixed solution was then heated to $40{ }^{\circ} \mathrm{C}$. Figure 5a showed that the premixed solution was freely flowing and bright yellow at $25{ }^{\circ} \mathrm{C}$ and it transformed into a self-supporting yellow hydrogel at $40{ }^{\circ} \mathrm{C}$ (Figure 5b). The results showed that FITC-G(IIKK) $)_{3} \mathrm{I}-\mathrm{NH}_{2}$ can be successfully loaded into the hydrogel and the loading did not affect the sol-gel transition. 


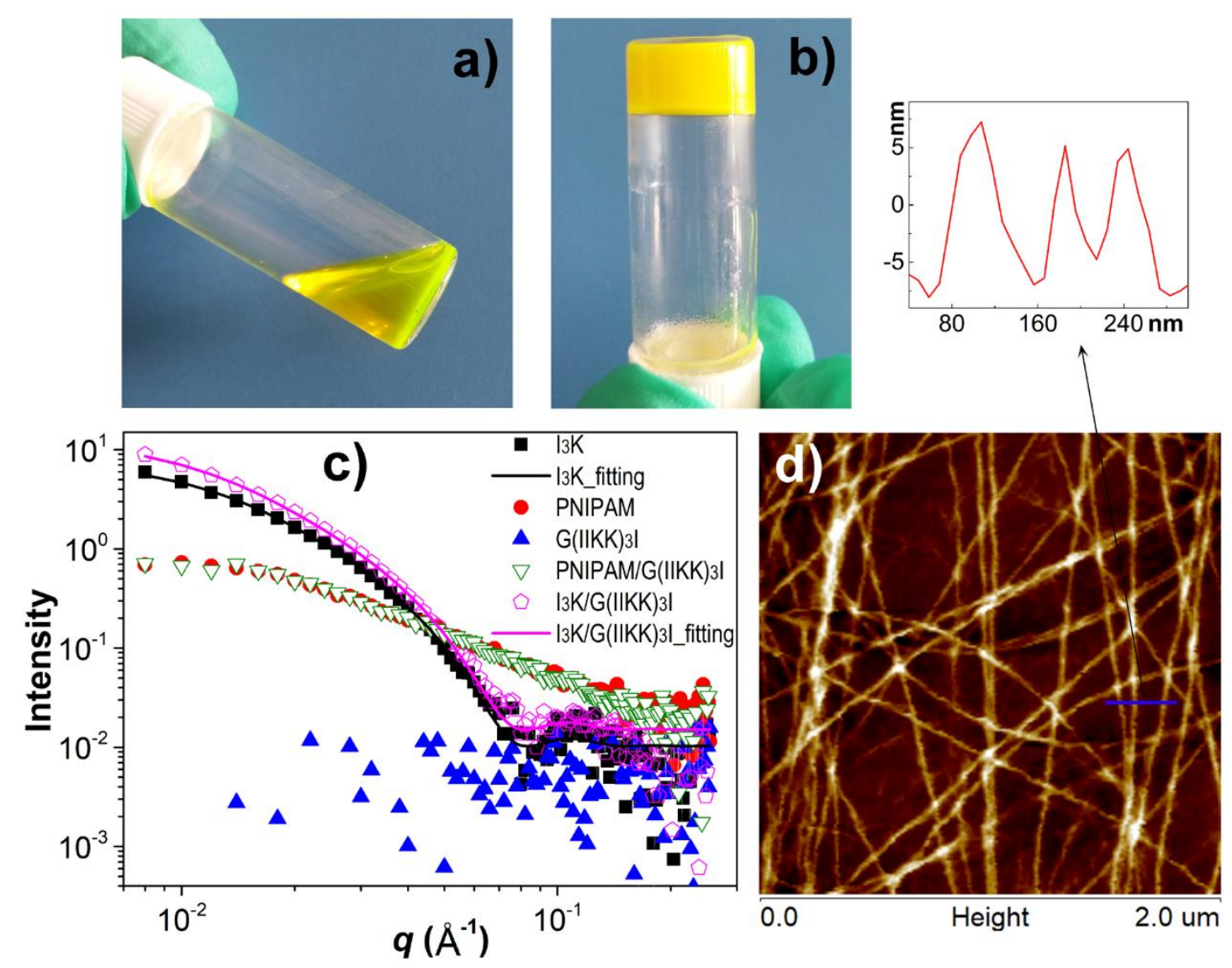

Figure 5. Photographs of the mixed solution of $\mathrm{I}_{3} \mathrm{~K}(6 \mathrm{mM}) / \mathrm{PNIPAM}(8$ $\mathrm{mg} / \mathrm{mL}) / \mathrm{FITC}-\mathrm{G}(\mathrm{IIKK})_{3} \mathrm{I}-\mathrm{NH}_{2}(1.0 \mathrm{mg} / \mathrm{mL})$ at (a) $25{ }^{\circ} \mathrm{C}$ and (b) $40{ }^{\circ} \mathrm{C}$. (c) SANS scattering curves as a function of momentum transfer $(q)$ of solutions of $\mathrm{I}_{3} \mathrm{~K}(6.0 \mathrm{mM})$, PNIPAM $(8.0 \mathrm{mg} / \mathrm{mL}), \mathrm{G}(\mathrm{IIKK})_{3} \mathrm{I}-\mathrm{NH}_{2}(1.0 \mathrm{mg} / \mathrm{mL})$, and the mixtures of $\mathrm{I}_{3} \mathrm{~K}(6.0$ $\mathrm{mM}) / \mathrm{G}(\mathrm{IIKK})_{3} \mathrm{I}(1.0 \mathrm{mg} / \mathrm{mL})$ and PNIPAM $(8.0 \mathrm{mg} / \mathrm{mL}) / \mathrm{G}(\mathrm{IIKK})_{3} \mathrm{I}-\mathrm{NH}_{2}(1.0 \mathrm{mg} / \mathrm{mL})$ in $\mathrm{D}_{2} \mathrm{O}$ at $25{ }^{\circ} \mathrm{C}$. (d) $\mathrm{AFM}$ images of the structures in the $\mathrm{I}_{3} \mathrm{~K}$ (6.0 $\mathrm{mM}) / \mathrm{G}(\mathrm{IIKK})_{3} \mathrm{I}-\mathrm{NH}_{2}(1.0 \mathrm{mg} / \mathrm{mL})$ mixtures.

Interactions between the hydrogel and the drug molecules determine the drug release from the hydrogel [9]. Due to the practical importance of the processes, the interactions between $\mathrm{G}(\mathrm{IIKK})_{3} \mathrm{I}-\mathrm{NH}_{2}$, PNIPAM and $\mathrm{I}_{3} \mathrm{~K}$ nanofibrils in solution were investigated using SANS (Figure 5c). G(IIKK) $)_{3} \mathrm{I}-\mathrm{NH}_{2}$ itself produced quite low scattering intensities over the whole $q$ range studied, indicating no aggregates were 
present in the solution. PNIPAM itself and the PNIPAM/G(IIKK) $)_{3} \mathrm{I}-\mathrm{NH}_{2}$ mixture gave almost the same profiles, indicating that there was no obvious interaction between them. However, compared with $\mathrm{I}_{3} \mathrm{~K}$ itself, the $\mathrm{I}_{3} \mathrm{~K} / \mathrm{G}(\mathrm{IIKK})_{3} \mathrm{I}-\mathrm{NH}_{2}$ mixture gave slightly higher intensities in the low $q$ region, indicating an increased aggregate size. The two curves were both well fitted with the flexible cylinder model, giving an average cylindrical radius of $4.6 \mathrm{~nm}$ for $\mathrm{I}_{3} \mathrm{~K}$ and a radius of $4.9 \mathrm{~nm}$ for the $\mathrm{I}_{3} \mathrm{~K} / \mathrm{G}(\mathrm{IIKK})_{3} \mathrm{I}-\mathrm{NH}_{2}$ mixture. The AFM results (Figure 5d) showed a radius of $5.2 \pm 1$ $\mathrm{nm}$ for the nanofibrils produced from the $\mathrm{I}_{3} \mathrm{~K} / \mathrm{G}(\mathrm{IIKK})_{3} \mathrm{I}-\mathrm{NH}_{2}$ mixture, which was slightly higher than that of $5.2 \pm 1 \mathrm{~nm}$ from the $\mathrm{I}_{3} \mathrm{~K}$ nanofirills from the SANS data (Figure 3a). Thus, both SANS and AFM results indicated that $\mathrm{G}(\mathrm{IIKK})_{3} \mathrm{I}-\mathrm{NH}_{2}$ bound into the $\mathrm{I}_{3} \mathrm{~K}$ nanofibrils, leading to the increase of the nanofibrillar radii.

For possible drug delivery applications, the toxicity of the $\mathrm{I}_{3} \mathrm{~K} / \mathrm{PNIPAM}$ hydrogels was first evaluated against NIH 3T3 cells by using the MTT assay (Figure 6a). The results showed that the cells can grow well on the $\mathrm{I}_{3} \mathrm{~K} / \mathrm{PNIPAM}$ gels, though the gels gave slightly lower $\mathrm{A}_{490}$ values than on the TCPS plate. The release of $\mathrm{G}(\mathrm{IIKK})_{3} \mathrm{I}-\mathrm{NH}_{2}$ from the hydrogels at $40{ }^{\circ} \mathrm{C}$ was then studied and the results are shown in Figure $6 \mathrm{~b}$. The inset photograph in Figure $\mathbf{6 b}$ showed that the hydrogels retained their integrity and did not disintegrate in excess water at $40{ }^{\circ} \mathrm{C}$. Therefore, although the hydrogels were physically crosslinked only, they were quite stable for use in drug encapsulation and release. 

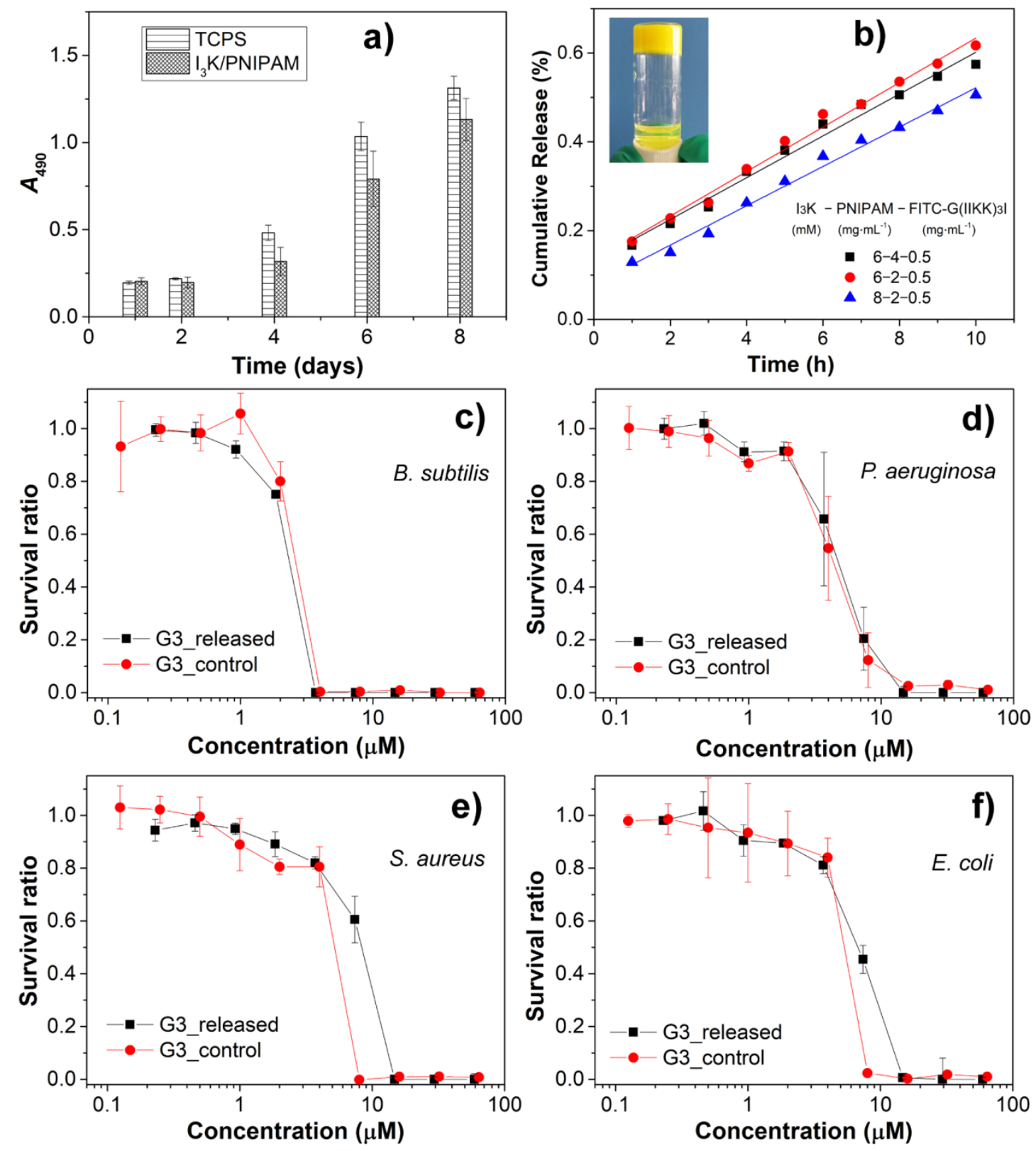

Figure 6. (a) Cytotoxicity of the $\mathrm{I}_{3} \mathrm{~K} / \mathrm{PNIPAM}$ hydrogel against NIH $3 \mathrm{~T} 3$ cells as determined from the MTT assay. (b) The cumulative release of FITC-G(IIKK) $)_{3} \mathrm{I}-\mathrm{NH}_{2}$ as a function of time. The inset photograph is the $\mathrm{I}_{3} \mathrm{~K} / \mathrm{PNIPAM} / \mathrm{FITC}-\mathrm{G}(\mathrm{IIKK})_{3} \mathrm{I}-\mathrm{NH}_{2}$ mixed hydrogel after release in water for $1 \mathrm{~h}$ at $40{ }^{\circ} \mathrm{C}$, showing that the gel still held its integrity. The plots in $(\mathrm{c}, \mathrm{d}, \mathrm{e}, \mathrm{f})$ are the MTT results in the form of the survival ratio as a function of FITC-G(IIKK) $)_{3} \mathrm{I}-\mathrm{NH}_{2}$ concentration indicating the antibacterial efficacy of the released FITC-G(IIKK) $)_{3} \mathrm{I}-\mathrm{NH}_{2}$ against bacteria of B. subtilis, $P$. aeruginosa, S. aureus, and E. coli, respectively. Free $\mathrm{G}(\mathrm{IIKK})_{3} \mathrm{I}-\mathrm{NH}_{2}$ was used as a 
control.

The release curves showed that the cumulative amount of $\mathrm{G}(\mathrm{IIKK})_{3} \mathrm{I}-\mathrm{NH}_{2}$ that was released had a nearly linear dependence on time over the time window in which data were take (Figure 6b). Although data are unavailable over the first $0.5-1$ hour, there is a clear concentration jump that indicates the initial burst. The subsequent linear release profile is consistent with the observations reported from drugs released from other PNIPAM derived polymeric hydrogels $[24,61]$. With the $I_{3} \mathrm{~K}$ concentration fixed at $6 \mathrm{mM}$, a change in PNIPAM concentration (e.g., 2 and $4 \mathrm{mg} / \mathrm{mL}$ ) had little influence on the release rate. While with the PNIPAM concentration fixed at $2 \mathrm{mg} / \mathrm{mL}$, a change of the $I_{3} \mathrm{~K}$ concentration from $6 \mathrm{mM}$ to $8 \mathrm{mM}$ resulted in a decrease of the release rate. The release results thus indicate that $\mathrm{G}(\mathrm{IIKK})_{3} \mathrm{I}-\mathrm{NH}_{2}$ had a stronger interaction with $\mathrm{I}_{3} \mathrm{~K}$, an observation confirmed by the SANS experiments. Although PNIPAM did not show interaction with $\mathrm{G}(\mathrm{IIKK})_{3} \mathrm{I}-\mathrm{NH}_{2}$ at $25{ }^{\circ} \mathrm{C}$, it collapsed into globules at $40{ }^{\circ} \mathrm{C}$, with its isopropyl groups associating into hydrophobic microdomains. These microdomains could also interact with the amphiphilic $\mathrm{G}(\mathrm{IIKK})_{3} \mathrm{I}-\mathrm{NH}_{2}$ via hydrophobic interactions. Thus, $\mathrm{G}(\mathrm{IIKK})_{3} \mathrm{I}-\mathrm{NH}_{2}$ encapsulation was attributed to the combined effects of interactions with both PNIPAM and the peptide nanofibrils. Also, the release of $\mathrm{G}(\mathrm{IIKK})_{3} \mathrm{I}-\mathrm{NH}_{2}$ exhibited a low initial burst, which is the usual case for drug release from the thermogels $[11,62,63]$. We suggest that the incorporation of the $\mathrm{G}(\mathrm{IIKK})_{3} \mathrm{I}-\mathrm{NH}_{2}$ molecules into the $\mathrm{I}_{3} \mathrm{~K}$ nanofibrils played crucial roles in determining the release profile and, significantly, reduced the time of the release of the initial burst.

One crucial aspect is whether the $\mathrm{G}(\mathrm{IIKK})_{3} \mathrm{I}-\mathrm{NH}_{2}$ molecules released from the 
hydrogel retain their antimicrobial capability. The antimicrobial efficacy of the $\mathrm{G}(\mathrm{IIKK})_{3} \mathrm{I}-\mathrm{NH}_{2}$ released from the hydrogel was assessed using the MTT method and the results are shown in Figure 6c, d, e, and f. The gel-released FITC-G(IIKK) ${ }_{3} \mathrm{I}-\mathrm{NH}_{2}$ gave MICs of $3.5 \mu \mathrm{M}$ against B. subtilis and $10.5 \mu \mathrm{M}$ against $P$. aeruginosa, $S$. aureus, and E. coli, respectively. These values are close to the MICs obtained from free $\mathrm{G}(\mathrm{IIKK})_{3} \mathrm{I}-\mathrm{NH}_{2}$. The results clearly show that the hydrogel-released $\mathrm{G}(\mathrm{IIKK})_{3} \mathrm{I}-\mathrm{NH}_{2}$ retains its high efficacy in killing bacteria, confirming the applicability of the system in drug delivery.

\section{CONCLUSIONS}

We successfully fabricated reversible thermoresponsive sol-gel peptide hydrogel systems by mixing the peptide nanofibrils with PNIPAM. The coil-to-globule phase transition of PNIPAM upon temperature increase was the main cause for the gelation. At temperatures above the LCST, the collapsed PNIPAM molecules form cross-links that connect different peptide nanofibrils, forming a solidified 3D network that incorporates a high content of water in a hydrogel. Antimicrobial peptides such as $\mathrm{G}(\mathrm{IIKK})_{3} \mathrm{I}-\mathrm{NH}_{2}$ can be easily loaded and its release above the LCST demonstrates a linear dynamic release process following a small initial rise, with the exact rate of release being adjustable by the concentration of short peptide $\mathrm{I}_{3} \mathrm{~K}$ due to the affinity between them. Since the gelling is physically driven, this type of hydrogels has a highly reversible sol-gel transition. Due to the peptide nanofibrils, the hydrogels bear structural similarity to the ECM environments of many tissues. Moreover, $T_{\text {sol-gel }}$ is around $33{ }^{\circ} \mathrm{C}$, slightly below body temperature. Therefore, the mixtures may find applications as injectable hydrogels, which can be formulated for in situ gelling systems for minimally invasive drug delivery or injectable tissue engineering 
scaffolds by using body temperature to trigger hydrogel formation $[18,59]$. Such a hydrogel also bears the advantage of easy elimination from the site by simply lowering the temperature below LCST and allowing the low viscosity mixture to be removed by small mechanical pressures.

\section{Notes}

The authors declare no competing financial interest.

\section{SUPPORT INFORMATION}

Photographs of $\mathrm{I}_{3} \mathrm{~K}$ and PNIPAM solutions at different temperature, the standard calculation curve of FITC-G(IIKK) $)_{3}$, the SANS fitting models and the fitted structural parameters are available free of charge via the Internet at http://pubs.acs.org.

\section{ACKNOWLEDGEMENTS}

This work was supported by the National Natural Science Foundation of China under grant numbers 21872173 and 21473255, and the Fundamental Research Funds for the Central Universities (17CX02050). We also acknowledge the UK Physical Sciences and Engineering Research Council (EPSRC, EP/F062966/1), Innovate UK (KTP008143, KTP009043) and the University of Manchester for funding support.

\section{REFERENCES}

[1] Jeong, B.; Kim, S.W.; Bae, Y.H., Thermosensitive sol-gel reversible hydrogels, Adv. Drug Deliver. Rev. 2012, 64, 154-162.

[2] Loh, X.J.; Li, J., Biodegradable thermosensitive copolymer hydrogels for drug delivery, Expert Opin. Ther. Pat. 2007, 17(8), 965-977.

[3] Yu, L.; Ding, J., Injectable hydrogels as unique biomedical materials, Chem. Soc. Rev. 2008, 37(8), 
1473-1481.

[4] Huynh, C.T.; Nguyen, M.K.; Lee, D.S., Injectable block copolymer hydrogels: achievements and future challenges for biomedical applications, Macromolecules 2011, 44(17), 6629-6636.

[5] Chen, Y.; Li, Y.; Shen, W.; Li, K.; Yu, L.; Chen, Q.; Ding, J., Controlled release of liraglutide using thermogelling polymers in treatment of diabetes, Sci. Rep. 2016, 6, 31593.

[6] McKenzie, M.; Betts, D.; Suh, A.; Bui, K.; Tang, R.; Liang, K.; Achilefu, S.; Kwon, G.S.; Cho, H., Proof-of-concept of polymeric sol-gels in multi-drug delivery and intraoperative image-guided surgery for peritoneal Ovarian cancer, Pharm. Res. 2016, 33(9), 2298-2306.

[7] Stile, R.A.; Burghardt, W.R.; Healy, K.E., Synthesis and characterization of injectable poly ( $\mathrm{N}$-isopropylacrylamide)-based hydrogels that support tissue formation in vitro, Macromolecules $\mathbf{1 9 9 9}$, 32(22), 7370-7379.

[8] Jeong, B.; Choi, Y.K.; Bae, Y.H.; Zentner, G.; Kim, S.W., New biodegradable polymers for injectable drug delivery systems, J. Control. Release 1999, 62(1), 109-114.

[9] Moon, H.J.; Ko, D.Y.; Park, M.H.; Joo, M.K.; Jeong, B., Temperature-responsive compounds as in situ gelling biomedical materials, Chem. Soc. Rev. 2012, 41(14), 4860-4883.

[10] Xi, L.; Wang, T.; Zhao, F.; Zheng, Q.J.; Li, X.N.; Luo, J.; Liu, J.; Quan, D.P.; Ge, J., Evaluation of an injectable thermosensitive hydrogel as drug delivery implant for Ocular Glaucoma surgery, Plos One 2014, 9(6), e100632.

[11] Ko, D.Y.; Shinde, U.P.; Yeon, B.; Jeong, B., Recent progress of in situ formed gels for biomedical applications, Prog. Poly. Sci. 2013, 38(3), 672-701.

[12] Sun, J.; Liu, X.; Lei, Y.; Tang, M.; Dai, Z.; Yang, X.; Yu, X.; Yu, L.; Sun, X.; Ding, J., Sustained subconjunctival delivery of cyclosporine A using thermogelling polymers for glaucoma filtration surgery, J. Mater. Chem. B 2017, 5, 6400-6411.

[13] Xie, B.; Jin, L.; Luo, Z.; Yu, J.; Shi, S.; Zhang, Z.; Shen, M.; Chen, H.; Li, X.; Song, Z., An injectable thermosensitive polymeric hydrogel for sustained release of Avastin® to treat posterior segment disease, Int. J. Pharm. 2015, 490(1), 375-383.

[14] Kwon, J.S.; Yoon, S.M.; Kwon, D.Y.; Kim, D.Y.; Tai, G.Z.; Jin, L.M.; Song, B.; Lee, B.; Kim, J.H.; Han, D.K.; Min, B.H.; Kim, M.S., Injectable in situ-forming hydrogel for cartilage tissue engineering, $J$. Mater. Chem. B 2013, 1(26), 3314-3321.

[15] Kim, D.Y.; Kwon, D.Y.; Kwon, J.S.; Kim, J.H.; Min, B.H.; Kim, M.S., Stimuli-responsive injectable in situ-forming hydrogels for regenerative medicines, Polym. Rev. 2015, 55(3), 407-452.

[16] Ni, P.; Ding, Q.; Fan, M.; Liao, J.; Qian, Z.; Luo, J.; Li, X.; Luo, F.; Yang, Z.; Wei, Y., Injectable thermosensitive PEG-PCL-PEG hydrogel/acellular bone matrix composite for bone regeneration in cranial defects, Biomaterials 2014, 35(1), 236-248.

[17] Yang, J.-A; Yeom, J.; Hwang, B.W.; Hoffman, A.S.; Hahn, S.K., In situ-forming injectable hydrogels for regenerative medicine, Prog. Poly. Sci. 2014, 39(12), 1973-1986.

[18] Agarwal, P.; Rupenthal, I.D, Injectable implants for the sustained release of protein and peptide drugs, Drug Discov. Today 2013, 18(7), 337-349.

[19] Couffin-Hoarau, A.C.; Motulsky, A.; Delmas, P.; Leroux, J.C., In situ-forming pharmaceutical organogels based on the self-assembly of L-alanine derivatives, Pharm. Res. 2004, 21(3), 454-457.

[20] Shi, K.; Wang, Y.-L.; Qu, Y.; Liao, J.-F.; Chu, B.-Y.; Zhang, H.-P.; Luo, F.; Qian, Z.-Y., Synthesis, characterization, and application of reversible PDLLA-PEG-PDLLA copolymer thermogels in vitro and in vivo, Sci. Rep. 2016, 6, 19077.

[21] Heskins, M.; Guillet, J.E., Solution properties of poly(N-isopropylacrylamide), J. Macromol. Sci. 
1968, 2(8), 1441-1455.

[22] Bajpai, A.K.; Shukla, S.K.; Bhanu, S.; Kankane, S., Responsive polymers in controlled drug delivery, Prog. Poly. Sci. 2008, 33(11), 1088-1118.

[23] Schild, H.G., Poly(N-isopropylacrylamide): experiment, theory and application, Prog. Poly. Sci. 1992, 17(2), 163-249.

[24] Ashraf, S.; Park, H.-K.; Park, H.; Lee, S.-H., Snapshot of phase transition in thermoresponsive hydrogel PNIPAM: Role in drug delivery and tissue engineering, Macromol. Res. 2016, 24(4), 297-304.

[25] Ramkissoon-Ganorkar, C.; Liu, F.; Baudyš, M.; Kim, S.W., Modulating insulin-release profile from $\mathrm{pH} /$ thermosensitive polymeric beads through polymer molecular weight, J. Control. Release 1999, 59(3), 287-298.

[26] Shimizu, T.; Yamato, M.; Kikuchi, A.; Okano, T., Two-dimensional manipulation of cardiac myocyte sheets utilizing temperature-responsive culture dishes augments the pulsatile amplitude, Tissue Eng. 2001, 7(2), 141-151.

[27] Schmaljohann, D., Thermo- and pH-responsive polymers in drug delivery, Adv. Drug Deliv. Rev. 2006, 58(15), 1655-1670.

[28] Haq, M.A.; Su, Y.; Wang, D., PNIPAM Mechanical properties of PNIPAM based hydrogels: A review, Mater. Sci. Eng. C 2017, 70, 842-855.

[29] Han, C.K.; Bae, Y.H., Inverse thermally-reversible gelation of aqueous N-isopropylacrylamide copolymer solutions, Polymer 1998, 39(13), 2809-2814.

[30] Lin, H.-H.; Cheng, Y.-L., In-Situ Thermoreversible gelation of block and star copolymers of poly(ethylene glycol) and poly(N-isopropylacrylamide) of varying architectures, Macromolecules 2001, 34(11), 3710-3715.

[31] Wang, T.; Zheng, S.; Sun, W.; Liu, X.; Fu, S.; Tong, Z., Notch insensitive and self-healing PNIPAm-PAM-clay nanocomposite hydrogels, Soft Matter 2014, 10(19), 3506-3512.

[32] Haraguchi, K.; Uyama, K.; Tanimoto, H., Self-healing in nanocomposite hydrogels, Macromol. Rapid Commun. 2011, 32(16), 1253-1258.

[33] Liu, J.; Song, G.; He, C.; Wang, H., Self-healing in tough graphene oxide composite hydrogels, Macromol. Rapid Commun. 2013, 34(12), 1002-1007.

[34] Cong, H.-P.; Wang, P.; Yu, S.-H., Stretchable and Self-healing graphene oxide-polymer composite hydrogels: a dual-network design, Chem. Mater. 2013, 25(16), 3357-3362.

[35] Wang, J.; Liu, K.; Xing, R.; Yan, X., Peptide self-assembly: thermodynamics and kinetics, Chem. Soc. Rev. 2016, 45(20), 5589-5604.

[36] Gazit, E., Self-assembled peptide nanostructures: the design of molecular building blocks and their technological utilization, Chem. Soc. Rev. 2007, 36(8), 1263-1269.

[37] Ulijn, R.V., Peptide-Based Materials via Molecular Self-Assembly, in: C.-L. Jaime, S. Luigi, E.S. Winnie (Eds.), Self-Assembled Peptide Nanostructures: Advances and Applications in Nanobiotechnology, CRC Press, Taylor \& Francis Group, Boca Raton, 2012, pp. 67-92.

[38] Cao, M.; Lu, S.; Zhao, W.; Deng, L.; Wang, M.; Wang, J.; Zhou, P.; Wang, D.; Xu, H.; Lu, J.R., Peptide self-assembled nanostructures with distinct morphologies and properties fabricated by molecular design, ACS Appl. Mater. Interfaces 2017, 9(45), 39174-39184.

[39] Gao, J.; Tang, C.; Elsawy, M.A.; Smith, A.M.; Miller, A.F.; Saiani, A., Controlling self-assembling peptide hydrogel properties through network topology, Biomacromolecules 2017, 18(3), 826-834.

[40] Banwell, E.F.; Abelardo, E.S.; Adams, D.J.; Birchall, M.A.; Corrigan, A.; Donald, A.M.; Kirkland, 
M.; Serpell, L.C.; Butler, M.F.; Woolfson, D.N., Rational design and application of responsive [alpha]-helical peptide hydrogels, Nat. Mater. 2009, 8(7), 596-600.

[41] Collier, J.H.; Hu, B.H.; Ruberti, J.W.; Zhang, J.; Shum, P.; Thompson, D.H.; Messersmith, P.B., Thermally and photochemically triggered self-assembly of peptide hydrogels, J. Am. Chem. Soc. 2001, 123(38), 9463-9464.

[42] Xing, R.; Li, S.; Zhang, N.; Shen, G.; Möhwald, H.; Yan, X., Self-assembled injectable peptide hydrogels capable of triggering antitumor immune response, Biomacromolecules 2017, 18, 3514-3523.

[43] Wang, Q.; Mynar, J.L.; Yoshida, M.; Lee, E.; Lee, M.; Okuro, K.; Kinbara, K.; Aida, T., High-water-content mouldable hydrogels by mixing clay and a dendritic molecular binder, Nature 2010, 463, 339-343.

[44] Zhang, Y.; Tao, L.; Li, S.; Wei, Y., Synthesis of multiresponsive and dynamic chitosan-based hydrogels for controlled release of bioactive molecules, Biomacromolecules 2011, 12(8), 2894-2901.

[45] Sabzi, M.; Samadi, N.; Abbasi, F.; Mahdavinia, G.R.; Babaahmadi, M., Bioinspired fully physically cross-linked double network hydrogels with a robust, tough and self-healing structure, Mater. Sci. Eng. C 2017, 74, 374-381.

[46] Xu, H.; Wang, Y.; Ge, X.; Han, S.; Wang, S.; Zhou, P.; Shan, H.; Zhao, X.; Lu, J.R., Twisted nanotubes formed from ultrashort amphiphilic peptide $\mathrm{I}_{3} \mathrm{~K}$ and their templating for the fabrication of silica nanotubes, Chem. Mater. 2010, 22(18), 5165-5173.

[47] Cao, M.W.; Wang, Y.M.; Ge, X.; Cao, C.H.; Wang, J.; Xu, H.; Xia, D.H.; Zhao, X.B.; Lu, J.R., Effects of anions on nanostructuring of cationic amphiphilic peptides, J. Phys. Chem. B 2011, 115(41), 11862-11871.

[48] Chen, C.; Hu, J.; Zeng, P.; Pan, F.; Yaseen, M.; Xu, H.; Lu, J.R., Molecular mechanisms of anticancer action and cell selectivity of short $\alpha$-helical peptides, Biomaterials 2014, 35(5), 1552-1561.

[49] Chen, C.; Hu, J.; Zeng, P.; Chen, Y.; Xu, H.; Lu, J.R., High cell selectivity and low-level antibacterial resistance of designed amphiphilic peptide $\mathrm{G}(\mathrm{IIKK})_{3} \mathrm{I}-\mathrm{NH}_{2}$, ACS Appl. Mater. Interfaces 2014, 6(19), 16529-16536.

[50] Maslovskis, A.; Guilbaud, J.B.; Grillo, I.; Hodson, N.; Miller, A.F.; Saiani, A., Self-assembling peptide/thermoresponsive polymer composite hydrogels: effect of peptide - polymer interactions on hydrogel properties, Langmuir 2014, 30(34), 10471-10480.

[51] Xu, H.; Wang, J.; Han, S.; Wang, J.; Yu, D.; Zhang, H.; Xia, D.H.; Zhao, X.B.; Waigh, T.A.; Lu, J.R, Hydrophobic-region-induced transitions in self-assembled peptide nanostructures, Langmuir 2008, 25(7), 4115-4123.

[52] Chen, C.X.; Zhang, Y.; Fei, R.; Cao, C.; Wang, M.; Wang, J.Q.; Bai, J.; Cox, H.; Waigh, T.A.; Lu, J.R.; Xu, H., Hydrogelation of the short self-assembling peptide $\mathrm{I}_{3} \mathrm{QGK}$ Regulated by transglutaminase and use for rapid hemostasis, ACS Appl. Mater. Interfaces 2016, 8(28), 17833-17841.

[53] Smith, A.M.; Williams, R.J.; Tang, C.; Coppo, P.; Collins, R.F.; Turner, M.L.; Saiani, A.; Ulijn, R.V., Fmoc-diphenylalanine self-assembles to a hydrogel via a novel architecture based on $\pi-\pi$ interlocked $\beta$-sheets, Adv. Mater. 2008, 20(1), 37-41.

[54] Pandey, N.; Hakamivala, A.;Xu, C.; Hariharan, P.; Radionov, B.; Huang, Z.; Liao, J.; Tang, L.; Zimmern, P.; Nguyen, K.T.; Hong, Y., Biodegradable nanoparticles enhanced adhesiveness of mussel-like hydrogels at tissue interface, Adv. Healthc. Mater. 2018, 7(7), 1701069.

[55] Zhao, Y.; Wang, J. .Q.; Deng, L.; Zhou, P.; Wang, S.J.; Wang, Y.; Xu, H.; Lu, J.R., Tuning the self-assembly of short peptides via sequence variations, Langmuir 2013, 29(44), 13457-64.

[56] Georgiades, P.; di Cola, E.; Heenan, R.K.; Pudney, P.D.A.; Thornton, D.J.; Waigh, T.A., A 
combined small-angle X-ray and neutron scattering study of the structure of purified soluble gastrointestinal mucins, Biopolymers 2014, 101(12), 1154-1164.

[57] Nishi, K.; Hiroi, T.; Hashimoto, K.; Fujii, K.; Han, Y.-S.; Kim, T.-H.; Katsumoto, Y.; Shibayama, M., SANS and DLS study of tacticity effects on hydrophobicity and phase separation of poly(N-isopropylacrylamide), Macromolecules 2013, 46(15), 6225-6232.

[58] Cheng, J.; Shan, G.; Pan, P., Triple stimuli-responsive N-isopropylacrylamide copolymer toward metal ion recognition and adsorption via a thermally induced sol-gel transition, Ind. Eng. Chem. Res. 2017, 56(5), 1223-1232.

[59] Ruel-Gariépy, E.; Leroux, J.-C., In situ-forming hydrogels - review of temperature-sensitive systems, Eur. J. Pharm. Biopharm. 2004, 58(2), 409-426.

[60] Hu, J.; Chen, C.X.; Zhang, S.Z.; Zhao, X.C..; Xu, H.; Zhao, X.B.; Lu, J.R., Designed antimicrobial and antitumor peptides with high selectivity, Biomacromolecules 2011, 12, 3839-3843.

[61] Okuyama, Y.; Yoshida, R.; Sakai, K.; Okano, T.; Sakurai, Y., Swelling controlled zero order and sigmoidal drug release from thermo-responsive poly(N-isopropylacrylamide-co-butyl methacrylate) hydrogel, J. Biomater. Sci. 1993, 4(5), 545-556.

[62] Yeo, Y.; Park, K., Control of encapsulation efficiency and initial burst in polymeric microparticle systems, Arch. Pharm. Res. 2004, 27(1), 1-12.

[63] Park, M.-R.; Chun, C.; Ahn, S.-W.; Ki, M.-H.; Cho, C.-S.; Song, S.-C., Cationic and thermosensitive protamine conjugated gels for enhancing sustained human growth hormone delivery, Biomaterials 2010, 31(6), 1349-1359.

TOC:

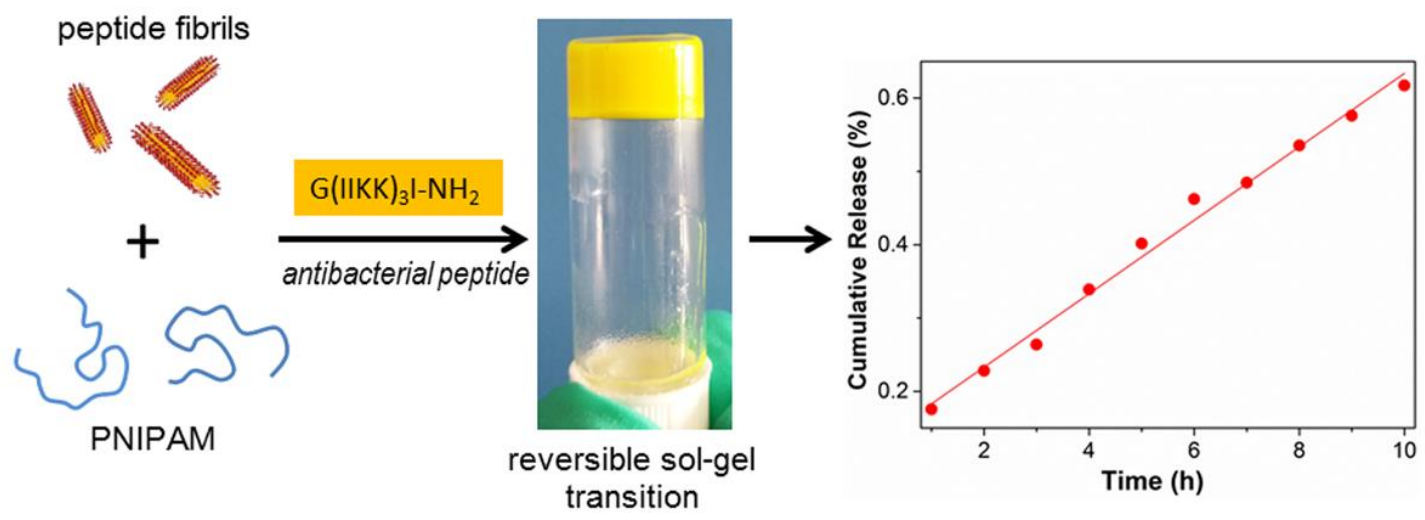




\section{Supporting Information}

\section{Reversible Thermoresponsive Peptide/PNIPAM Hydrogels for Controlled Drug}

\section{Delivery}

Meiwen Cao, ${ }^{*}{ }^{\dagger}$ Yu Wang, ${ }^{\dagger}$ Xuzhi Hu, ${ }^{\ddagger}$ Haoning Gong, ${ }^{\ddagger}$ Ruiheng Li, ${ }^{\ddagger}$ Henry Cox,${ }^{\ddagger}$ Jing Zhang, ${ }^{\ddagger}$ Thomas A. Waigh, ${ }^{\ddagger,+}$ Hai Xu,,${ }^{* \dagger}$ and Jian Ren $\mathrm{Lu}^{*},+$

${ }^{\dagger}$ State Key Laboratory of Heavy Oil Processing and Centre for Bioengineering and Biotechnology, College of Chemical Engineering, China University of Petroleum (East China), 66 Changjiang West Road, Qingdao 266580, China

${ }^{\ddagger}$ Biological Physics Laboratory, School of Physics and Astronomy, University of Manchester, Schuster Building, Oxford Road, Manchester M13 9PL, U.K.

+ Photon Science Institute, University of Manchester, Oxford Rd., Manchester, M13 9PL, U.K.

\section{Corresponding Authors}

* E-mail: $\quad$ mwcao@upc.edu.cn $\quad$ (M.C.); $\quad$ xuh@upc.edu.cn $\quad$ (H.X.); j.lu@manchester.ac.uk (J.R.L.)

Total of 5 figures, 2 tables and 6 pages in the SI document 

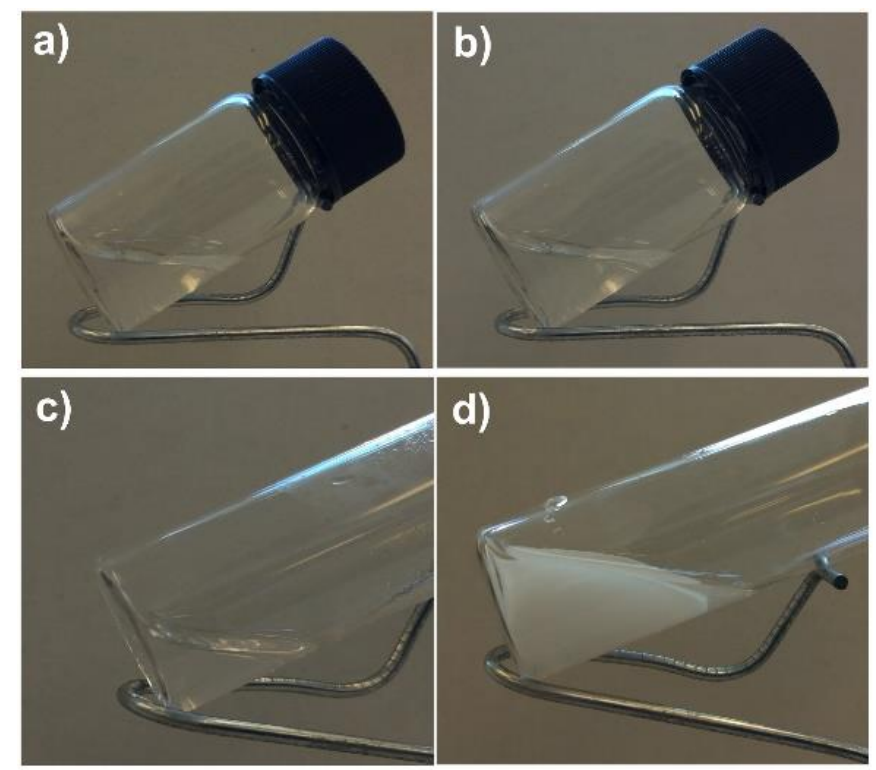

Figure S1. The photographs showing the state of the free solutions of $\mathrm{I}_{3} \mathrm{~K}(8 \mathrm{mM})$ and PNIPAM (20 mg/mL) at different temperatures: (a) $\mathrm{I}_{3} \mathrm{~K}$ at $25{ }^{\circ} \mathrm{C}$, (b) $\mathrm{I}_{3} \mathrm{~K}$ at $40{ }^{\circ} \mathrm{C}$, (c) PNIPAM at $25^{\circ} \mathrm{C}$, and (d) PNIPAM at $40{ }^{\circ} \mathrm{C}$.
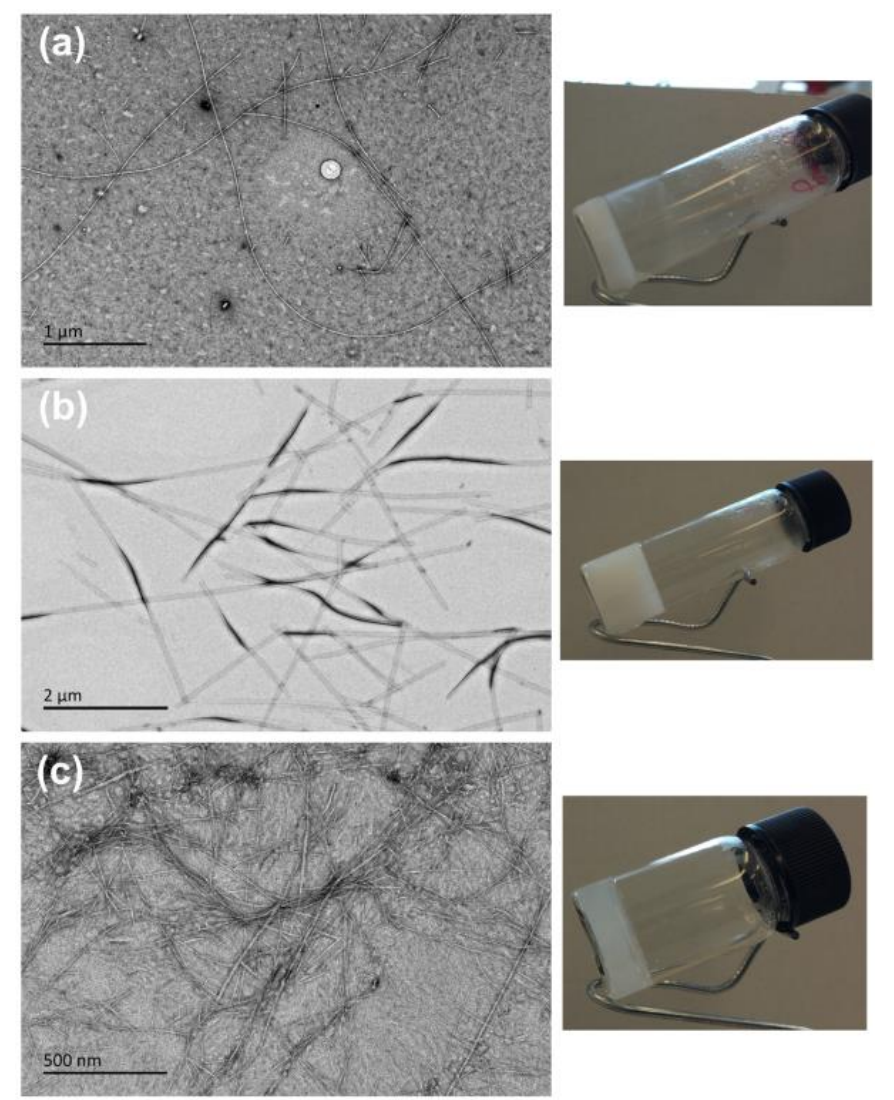

Figure S2. TEM images of the self-assembled structures (a) $\mathrm{A}_{6} \mathrm{~K}(4 \mathrm{mM})$, (b) $\mathrm{I}_{3} \mathrm{QGK}$ (4 mM), and (c) Fmoc-FF-OH (3 mM). $\mathrm{A}_{6} \mathrm{~K}$ self-assembles into long nanofibers with 
micrometer length and diameter of $8.0 \pm 1.5 \mathrm{~nm}$. $\mathrm{I}_{3} \mathrm{QGK}$ forms nanoribbons with micrometer length and width of $30-55 \mathrm{~nm}$. Fmoc-FF-COOH produces micrometer long fibrils with diameters of $5.5 \pm 0.5 \mathrm{~nm}$ and $10.0 \pm 1.0 \mathrm{~nm}$ and some fibril bundles. The right panel shows the corresponding photographs of the peptide/PNIPAM mixtures at $40{ }^{\circ} \mathrm{C}$, (a) $\mathrm{A}_{6} \mathrm{~K}(4 \mathrm{mM})+\operatorname{PNIPAM}(15 \mathrm{mg} / \mathrm{mL})$, (b) $\mathrm{I}_{3} \mathrm{QGK}(4 \mathrm{mM})+$ PNIPAM (10 mg/mL), and (c) Fmoc-FF-OH (3 mM) + PNIPAM (5 mg/mL).
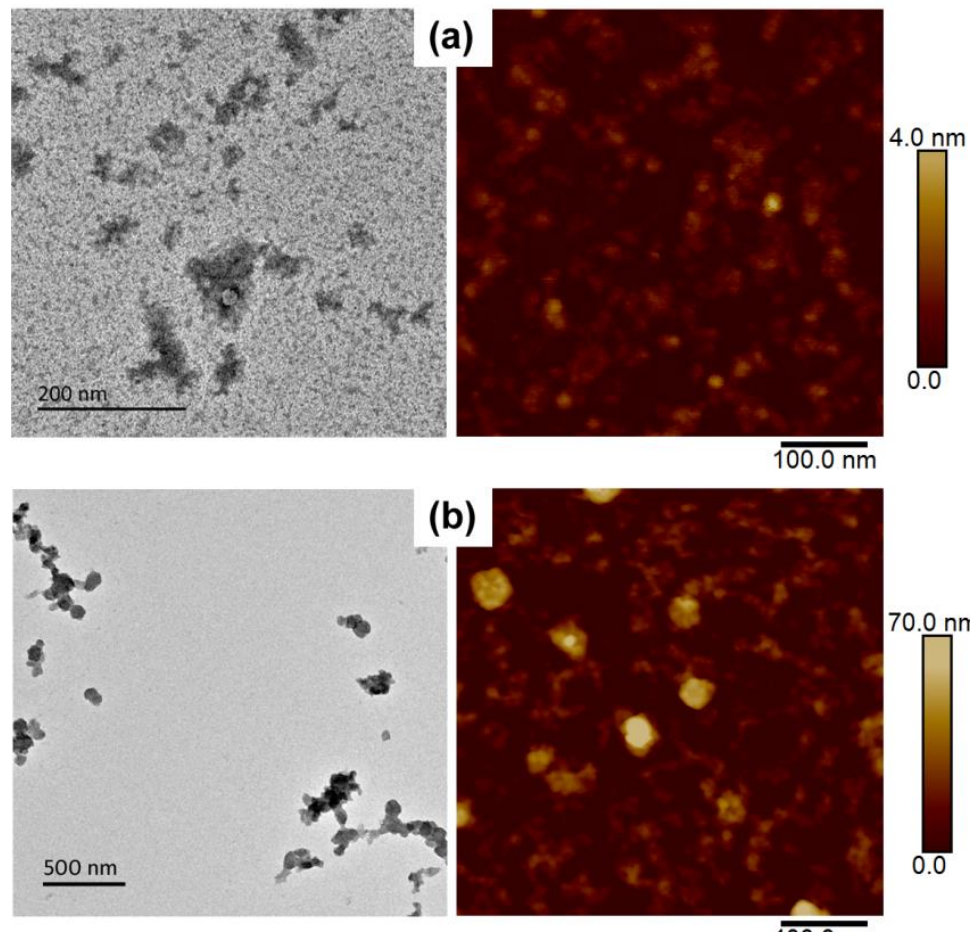

(b)

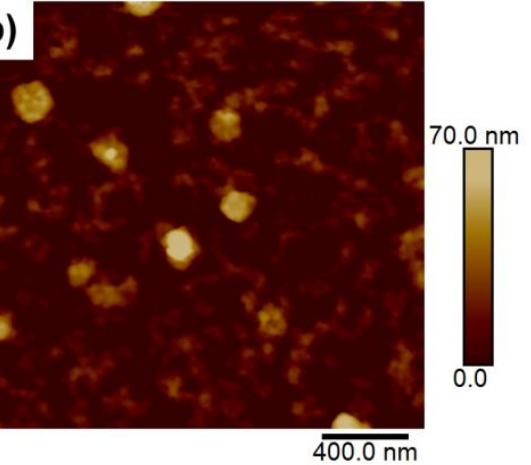

Figure S3. TEM (left panel) and AFM (right panel) images of PNIPAM aggregates (10 mg/mL, Tris buffer $\mathrm{pH} 7.4$ ) at different temperatures, (a) $25{ }^{\circ} \mathrm{C}$ and (b) $40{ }^{\circ} \mathrm{C}$. PNIPAM at $25{ }^{\circ} \mathrm{C}$ produced loose thin aggregates due to surface-induced concentrating effect and aggregation. PNIPAM at $40{ }^{\circ} \mathrm{C}$ produced larger dense aggregates due to temperature-induced coil-to-globule transition, though the surface effects could be completely excluded. 


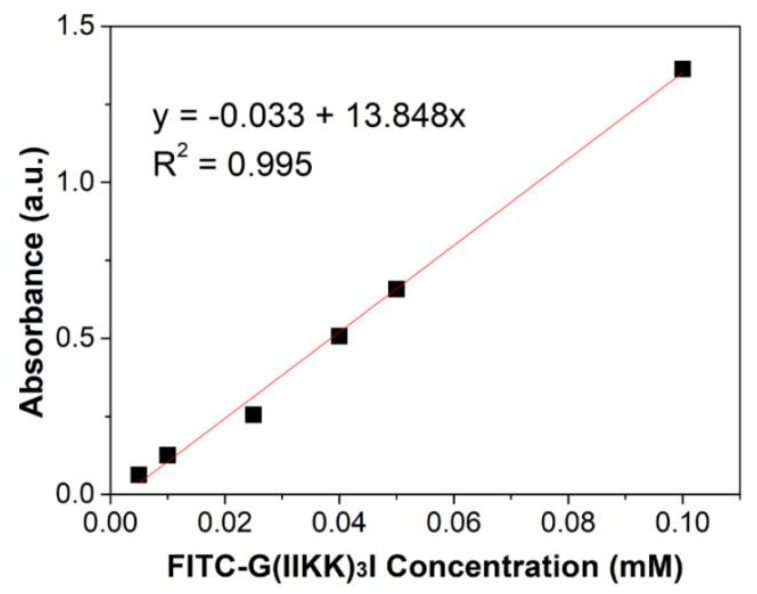

Figure S4. The standard calculation curve derived by linear fitting of the absorbance at $495 \mathrm{~nm}$ of FITC-G(IIKK) $)_{3} \mathrm{I}-\mathrm{NH}_{2}$ solutions of different concentration.

Table S1. The best-fitted structural parameters for the SANS data as shown in Figure 3. The unit for the sld (scattering length density) is $\AA^{-2}$.

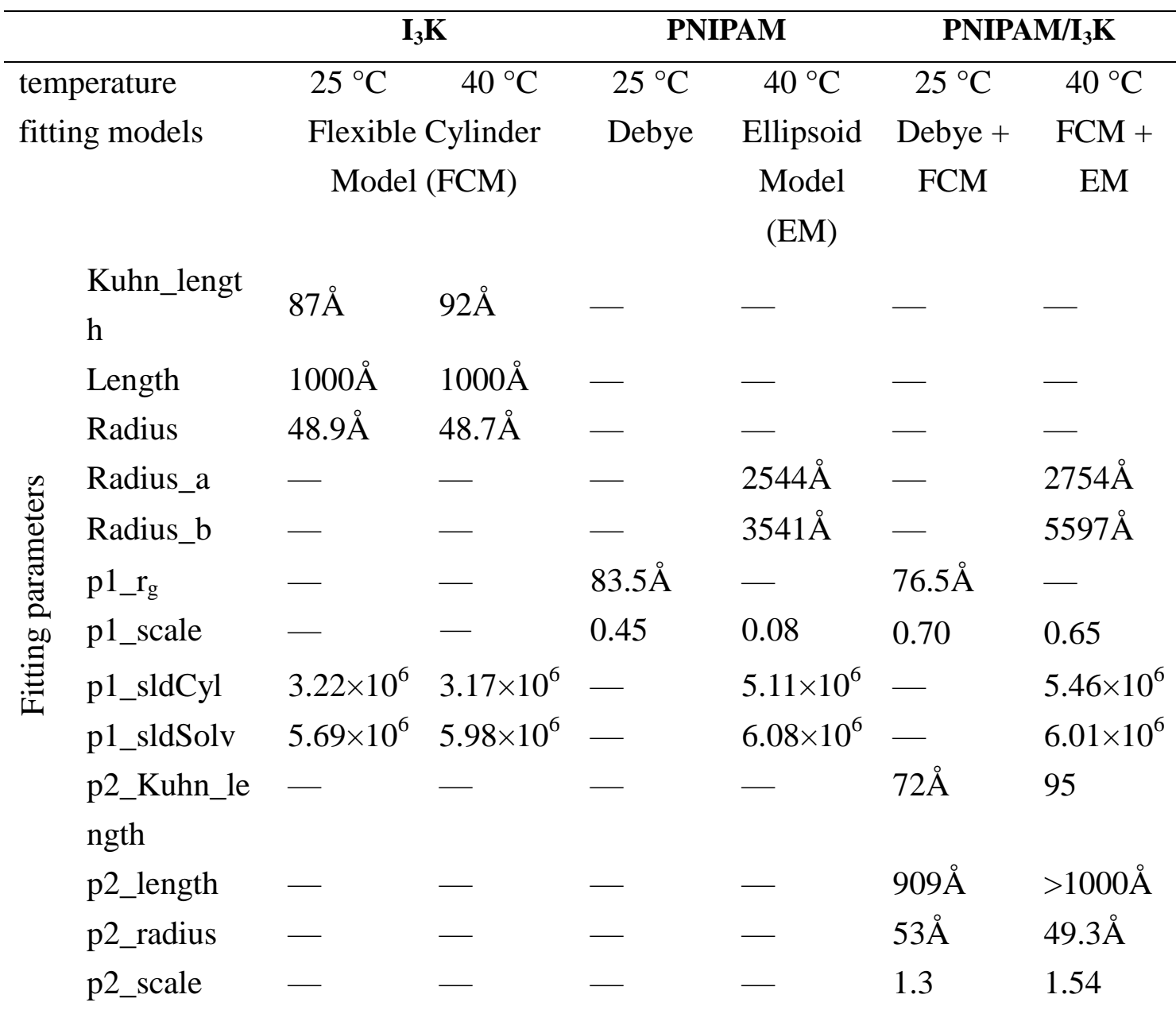




\begin{tabular}{|c|c|c|c|c|c|c|}
\hline p2_sldCyl & - & - & - & - & $4.49 \times 10^{6}$ & $5.42 \times 10^{6}$ \\
\hline p2_sldSolv & - & - & & & $6.26 \times 10^{6}$ & $5.54 \times 10^{6}$ \\
\hline ale_factor & - & - & - & - & 0.23 & 0.36 \\
\hline
\end{tabular}

The models used for fitting the small angle neutron scattering (SANS) data are detailed as follows.

(1) The Debye Model:

The Debye model is for the linear polymer chain. The radius of gyration $\left(r_{g}\right)$, a scale factor, and a constant background term are included in the calculation. The fundamental theory of the Debye Model can be found from reference [Roe et al., $2000]^{1}$.

(2) The Flexible Cylinder Model:

The fundamental theory of the flexible cylinder model can be found from references [Pedersen et.al, Macromolecules 1996, 29, 7602] ${ }^{2}$ and [Chen et. al, Langmuir 2006, $22,6539]^{3}$.

In this model, the chain of contour length can be described as a chain of some number of locally stiff segments of length $\mathrm{L}_{p}\left(\mathrm{~L}_{p}\right.$ : the persistence length, the length along the chain over which the flexible cylinder can be considered as a rigid rod). The Kuhn length $=2 \times \mathrm{L}_{p}$. In the fitting parameters, the sldCyl and sldSolv represent SLD (chain/cylinder) and SLD (solvent), respectively.

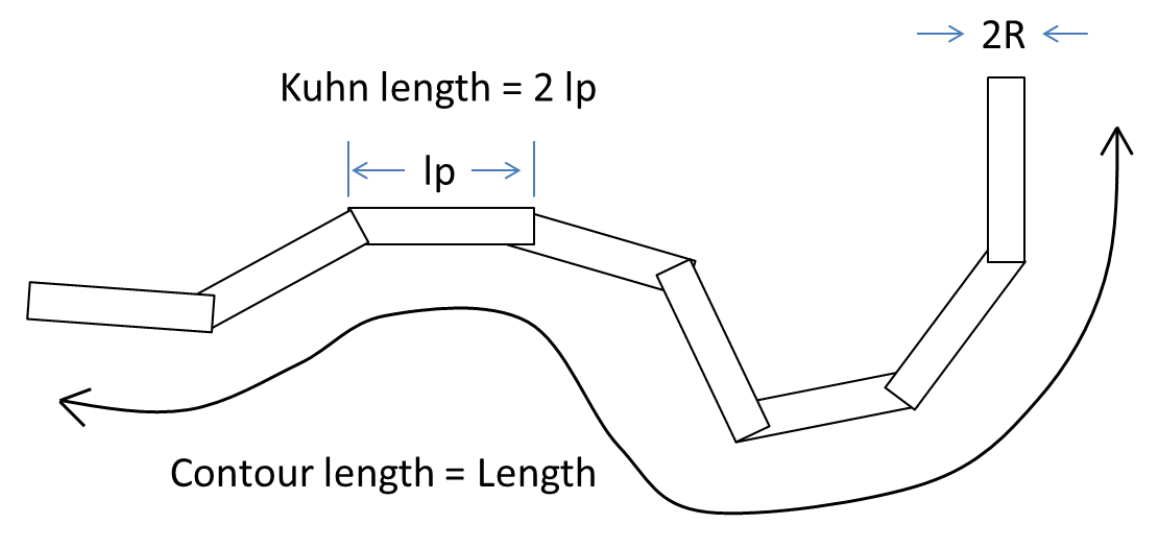


Figure S5. Scheme for the Flexible Cylinder Model.

(3) The Ellipsoid Model:

This model provides the form factor for an ellipsoid (ellipsoid of revolution) with uniform scattering length density. The form factor is normalized by the particle volume. The fundamental theory of the FlexCylEllipX Model can be found from reference [Feigin, 1987] ${ }^{4}$.

Table S2. The best-fitted structural parameters for the SANS data as shown in Figure 5c.

\begin{tabular}{|c|c|c|c|}
\hline & & $\mathbf{I}_{3} \mathbf{K}$ & $\mathbf{I}_{3} \mathrm{~K} / \mathbf{G}(\mathrm{IIKK})_{3} \mathbf{I}$ \\
\hline \multicolumn{2}{|c|}{ temperature } & $25^{\circ} \mathrm{C}$ & $25^{\circ} \mathrm{C}$ \\
\hline \multicolumn{2}{|c|}{ fitting models } & $\mathrm{FCM}$ & FCM \\
\hline \multirow{5}{*}{ 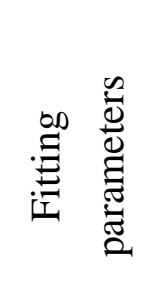 } & Kuhn_length & $11 \AA$ & $9 \AA$ \\
\hline & Length & $4247 \AA$ & $6042 \AA$ \\
\hline & Radius & $46.1 \AA$ & $49.2 \AA$ \\
\hline & sldCyl & $3.58 \times 10^{6}$ & $3.69 \times 10^{6}$ \\
\hline & sldSolv & $6.39 \times 10^{6}$ & $6.50 \times 10^{6}$ \\
\hline
\end{tabular}

\section{References:}

1. Roe, R.-J., Methods of X-Ray and Neutron Scattering in Polymer Science, Oxford University Press, New York, 2000.

2. Pedersen, J. S.; Schurtenberger, P., Scattering Functions of Semiflexible Polymers with and without Excluded Volume Effects. Macromolecules 1996, 29 (23), 7602-7612.

3. Chen, W.-R.; Butler, P. D.; Magid, L. J., Incorporating Intermicellar Interactions in the Fitting of SANS Data from Cationic Wormlike Micelles. Langmuir 2006, 22 (15), 6539-6548.

4. Feigin, L.; Svergun, D. I., Structure Analysis by Small-Angle X-Ray and Neutron Scattering. Springer: Plenum, New York, 1987. 
